ARTICLE

\title{
Separating mitochondrial protein assembly and endoplasmic reticulum tethering by selective coupling of Mdm10
}

Lars Ellenrieder ${ }^{1,2}$, Łukasz Opaliński ${ }^{1, \dagger}$, Lars Becker ${ }^{3}$, Vivien Krüger ${ }^{3}$, Oliver Mirus ${ }^{4}$, Sebastian P. Straub ${ }^{1,2}$, Katharina Ebell ${ }^{3}$, Nadine Flinner ${ }^{4, \dagger}$, Sebastian B. Stiller ${ }^{1}$, Bernard Guiard ${ }^{5}$, Chris Meisinger ${ }^{1,6}$, Nils Wiedemann ${ }^{1,6}$, Enrico Schleiff ${ }^{4,7}$, Richard Wagner ${ }^{3,8}$, Nikolaus Pfanner ${ }^{1,6} \&$ Thomas Becker $^{1,6}$

The endoplasmic reticulum-mitochondria encounter structure (ERMES) connects the mitochondrial outer membrane with the ER. Multiple functions have been linked to ERMES, including maintenance of mitochondrial morphology, protein assembly and phospholipid homeostasis. Since the mitochondrial distribution and morphology protein Mdm10 is present in both ERMES and the mitochondrial sorting and assembly machinery (SAM), it is unknown how the ERMES functions are connected on a molecular level. Here we report that conserved surface areas on opposite sides of the Mdm10 $\beta$-barrel interact with SAM and ERMES, respectively. We generated point mutants to separate protein assembly (SAM) from morphology and phospholipid homeostasis (ERMES). Our study reveals that the $\beta$-barrel channel of Mdm10 serves different functions. Mdm10 promotes the biogenesis of $\alpha$-helical and $\beta$-barrel proteins at SAM and functions as integral membrane anchor of ERMES, demonstrating that SAM-mediated protein assembly is distinct from ER-mitochondria contact sites.

\footnotetext{
${ }^{1}$ Institute of Biochemistry and Molecular Biology, Centre for Biochemistry and Molecular Cell Research, Faculty of Medicine, University of Freiburg, Freiburg D79104, Germany. ${ }^{2}$ Faculty of Biology, University of Freiburg, Freiburg D-79104, Germany. ${ }^{3}$ Division of Biophysics, School of Biology/Chemistry, University of Osnabrück, Osnabrück D-49034, Germany. ${ }^{4}$ Molecular Cell Biology of Plants, University of Frankfurt, Frankfurt D-60438, Germany. ${ }^{5}$ Centre de Génétique Moléculaire, Centre National de la Recherche Scientifique, Gif-sur-Yvette 91190, France. ${ }^{6}$ BIOSS Centre for Biological Signalling Studies, University of Freiburg, Freiburg D-79104, Germany. ${ }^{7}$ Buchmann Institute of Molecular Life Sciences, Cluster of Excellence Macromolecular Complexes, University of Frankfurt, Frankfurt D-60438, Germany. ${ }^{8}$ Life Sciences \& Chemistry, Focus Area Health, Jacobs University Bremen, Bremen D-28759, Germany. $\dagger$ Present addresses: Faculty of Biotechnology, Department of Protein Engineering, University of Wroclaw, Wroclaw 50383, Poland (Ł.O.); Frankfurt Institute for Advanced Studies, University of Frankfurt, Frankfurt D-60438, Germany (N.F.). Correspondence and requests for materials should be addressed to N.P. (email: nikolaus.pfanner@biochemie.uni-freiburg.de) or to T.B. (email: thomas.becker@biochemie.uni-freiburg.de).
} 
$\mathrm{M}$ itochondria were originally considered to function as semi-autonomous organelles that produce ATP, yet are largely independent of the rest of the cell. This view has radically changed since it was found that mitochondria are deeply integrated into central cellular functions, from numerous metabolic pathways to protein and lipid biogenesis, signalling processes, quality control and apoptosis ${ }^{1-4}$. Recent studies led to the identification of contact sites between mitochondria and other cell organelles, providing strong evidence for the extensive integration of mitochondria into cellular homeostasis and organization $^{5-11}$.

The endoplasmic reticulum (ER)-mitochondria encounter structure (ERMES) forms a stable bridge between the ER membrane and the mitochondrial outer membrane ${ }^{5}$. The ERMES complex consists of four core components. The maintenance of mitochondrial morphology ( $\mathrm{Mmm} 1)$ protein is anchored in the ER membrane. The mitochondrial distribution and morphology proteins $\mathrm{Mdm} 10$ and $\mathrm{Mdm} 34(\mathrm{Mmm} 2)$ were reported to be integrated into the outer membrane of mitochondria, whereas $\mathrm{Mdm} 12$ is a peripheral membrane protein $^{5,12-14}$. The stable assembly of the four components into the ERMES complex connects both organelles, however, the molecular architecture of ERMES is not fully understood. A fifth subunit, the GTPase Gem1, associates with ERMES, but is present in substoichiometric amounts and is not required for formation of the ERMES complex ${ }^{15-17}$. Multiple mitochondrial functions have been linked to ERMES, including biogenesis and assembly of outer membrane proteins, lipid homeostasis, membrane dynamics, mitophagy and maintenance of mitochondrial morphology $5,11,18-24$. A molecular assignment of ERMES functions has been difficult and thus different views exist which functions are directly connected to ERMES and which are indirect effects. In case of mitochondrial inheritance, it was reported that inheritance defects of ERMES mutants were indirectly caused by defects of mitochondrial morphology ${ }^{17}$.

Whereas three ERMES core components, Mmm1, Mdm12 and Mdm34, are selectively located in the ERMES complex, the fourth one, Mdm10, has a dual localization. Mdm10 is part of both the ERMES complex and the sorting and assembly machinery (SAM) of the mitochondrial outer membrane $e^{18,19,21,25,26}$. The SAM complex is responsible for the membrane insertion of two types of newly synthesized mitochondrial outer membrane proteins, $\beta$-barrel proteins and some $\alpha$-helical proteins. SAM is thus required for the biogenesis and assembly of the main translocase of the outer membrane (TOM) that consists of both $\beta$-barrel and $\alpha$-helical proteins ${ }^{18,26-33}$. Mutants of Mdm10 disturb major ERMES-connected functions, including mitochondrial morphology, lipid homeostasis and protein assembly, yet it is open which molecular functions are performed by ERMES-bound Mdm10 and which ones by SAM-bound Mdm10. Remarkably, yeast cells lacking either Mmm1, Mdm12 or Mdm34 display alterations of the mitochondrial tubular network, of phospholipid profiles and of outer membrane protein assembly like $m d m 10 \Delta$ cells $^{5,13,19,25,34,35}$, although these components do not interact with SAM. Two explanations are conceivable to explain the mutant phenotypes: (i) either the association of Mdm10 with the SAM complex is functionally not relevant and thus $m d m 10 \Delta$ cells just display ERMES defects; or (ii) Mdm10 and the other ERMES core components are so closely linked that the deletion of entire components will impact on Mdm10 functions. Indeed, the Mdm10 molecules present in SAM or ERMES do not form strictly separate pools, but $\mathrm{Mdm} 10$ can shuttle between both complexes, supporting the second view ${ }^{19,31}$. Tom7, which has a dual localization at TOM and Mdm10, binds to SAM-free
Mdm10 and thus favours a release of Mdm10 from SAM and its association with ERMES $21,32,36$.

It is unknown how Mdm10 is recruited to ERMES and/or SAM. A functional dissection of Mdm10 and its binding partners will represent a key step towards assigning ERMES- and SAMspecific functions. In this study, we perform a systematic structure-function analysis of Mdm10 and its interaction with partners. We report that conserved surface areas on opposite sides of the Mdm10 $\beta$-barrel are crucial for the recruitment of Mdm10 to either ERMES or SAM. Assembly of mitochondrial outer membrane proteins is specifically linked to SAM-bound Mdm10, whereas the maintenance of mitochondrial morphology and lipid homeostasis is linked to ERMES-bound Mdm10. Our findings reveal that the $\beta$-barrel of Mdm10 plays different roles. It forms a channel for the SAM-mediated insertion of Tom 22 into the outer membrane and serves as integral membrane anchor of ERMES at mitochondria, thus promoting its functions in membrane morphology and lipid transfer.

\section{Results}

SAM and ERMES bind to opposite sides of Mdm10. Mdm10 belongs to the VDAC/Tom40 superfamily of eukaryotic $\beta$-barrel proteins ${ }^{37,38}$. The members of the superfamily consist of 19 antiparallel $\beta$-strands with a similar fold, connected by loops of variable length ${ }^{37-39}$. To define SAM- and ERMES-specific functions of $\mathrm{Mdm} 10$, we asked if Mdm10 contains different binding sites for its partner proteins. To identify potential binding sites, we analysed conserved regions of Mdm10 based on the observation that evolutionarily conserved (identical or similar) amino-acid residues, in particular hydrophobic and aromatic residues, are often enriched in protein-protein interfaces ${ }^{40}$. Since deletion of various loops of Mdm10 neither affected cell growth nor the interaction of Mdm10 with ERMES or SAM ${ }^{38}$, we focused on the membrane-integrated $\beta$-barrel domain. Mdm10 contains two conserved regions on opposite sides of its $\beta$-barrel (Fig. 1a) ${ }^{38}$ : a surface groove formed between $\beta$-strands 4 and 5 is flanked by an invariant glycine residue (G144) and two adjacent aromatic residues of $\beta$-strand 3 (conserved Y73 and Y75), whereas a strip of several conserved aromatic residues is located on the other side (including Y296 and F298 on $\beta$-strand 14 and Y301 on the subsequent loop). To study the functions of the conserved regions, we replaced aromatic residues by alanine and the glycine residue by leucine in yeast. The resulting mutant cells were impaired in growth at elevated temperature, in particular on non-fermentable medium when a high activity of mitochondria is required (Fig. 1b). To study the interaction of Mdm10 with its partners, mitochondria were lysed with the non-ionic detergent digitonin, and Mdm10-containing complexes were purified by co-immunoprecipitation. Strikingly, the mutant mitochondria showed selective differences in the interaction of $\mathrm{Mdm} 10$ with SAM, ERMES and Tom7. The co-purification of Sam35 was strongly reduced in the Mdm10 ${ }^{\mathrm{Y} 73,75 \mathrm{~A}}$ mitochondria, whereas the co-purification of ERMES subunits (Mmm1 and Mdm12) was unaffected (Fig. 1c, lane 8). In contrast, Mdm10 Y296A,F298A mitochondria were impaired in the interaction of $\mathrm{Mmml}$ and Mdm12, but not of Sam35, with Mdm10 (Fig. 1c, lane 10). Moreover, Mdm10 G144L mitochondria were impaired in the co-purification of Tom7, but not of Sam 35 or ERMES subunits (Fig. 1c, lane 9). We conclude that different surface areas of the Mdm10 $\beta$-barrel are crucial for the interaction with SAM and ERMES.

To exclude indirect effects of the $m d m 10$ site-specific mutants, we performed a number of control experiments. (i) The steadystate levels of various proteins, including SAM and ERMES subunits, were not or only mildly affected in the mutant 
a
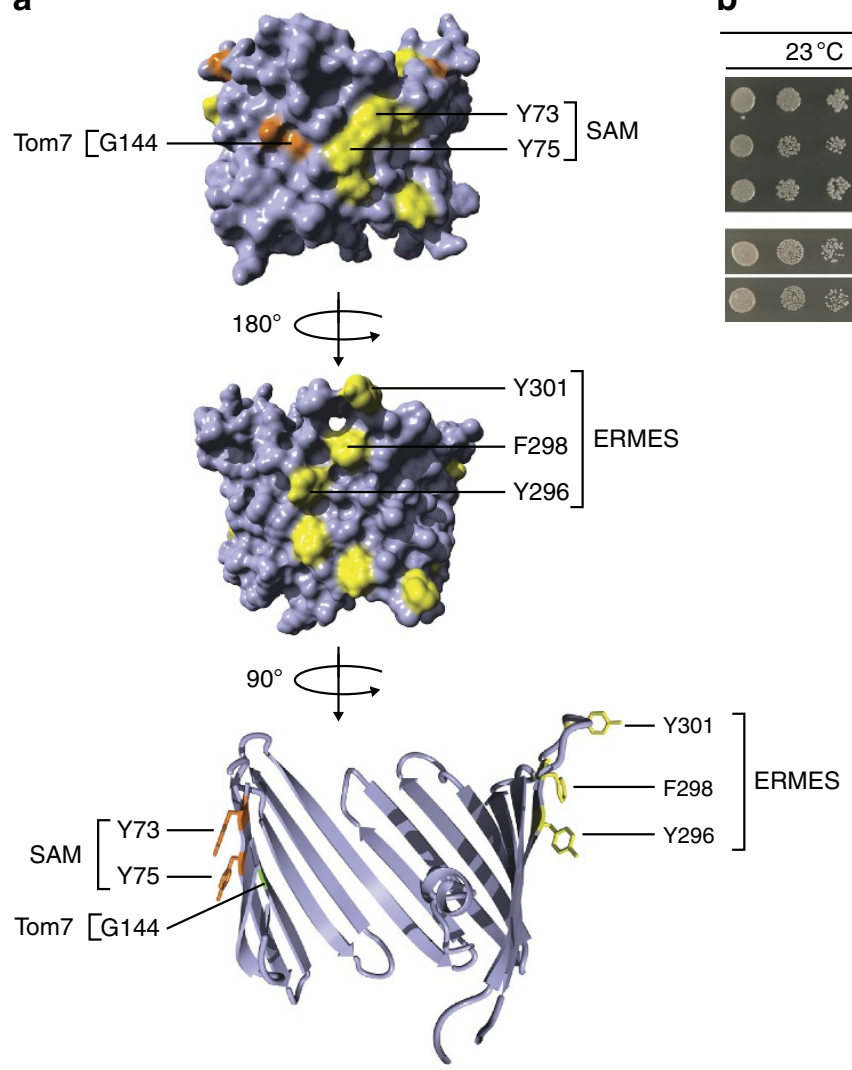

b

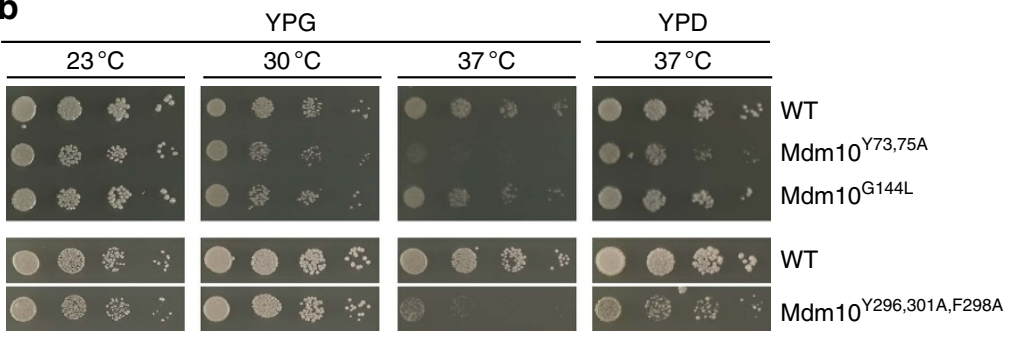

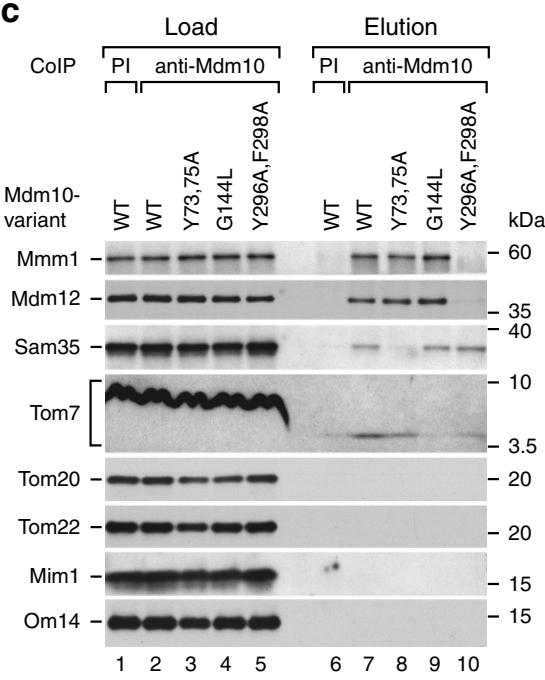

Figure 1 | Identification of protein interaction sites on the $\beta$-barrel surface of Mdm10. (a) Homology model of the $\beta$-barrel domain of Mdm10 (ref. 38 ). Long hydrophilic loops are shortened. Conserved amino-acid residues and a conserved hydrophobic groove on one side of the $\beta$-barrel (yellow (Phe, Trp and Tyr) and orange (Ala/Gly); top panel) and a strip of conserved aromatic residues on the other side of the barrel (yellow; middle panel) are highlighted. Amino-acid residues that were replaced by mutational analysis in this study are labelled. Bottom, the $\beta$-barrel of Mdm10 is depicted as cut open model in a ribbon representation. (b) Serial dilutions of yeast strains expressing wild-type (WT) or mutant forms of MDM10 were grown on agar plates containing either glycerol (YPG) or glucose (YPD) as carbon source at different temperatures. (c) Mitochondria isolated from cells expressing WT or mutant forms of MDM10 were solubilized with digitonin and subjected to co-immunoprecipitation (ColP) using antibodies raised against Mdm10. Samples were analysed by SDS-polyacrylamide gel electrophoresis and immunodetection of the indicated proteins. Load 2\%, elution $100 \%$. PI, pre-immune serum.

mitochondria (Supplementary Figs 1a and 2a). (ii) Cells with a deletion of MDM10 frequently show a loss of mtDNA ${ }^{25}$, leading to indirect effects on mitochondrial structure and function. The $m d m 10$ site-specific mutants were able to grow on nonfermentable medium (Fig. 1b) and the oxidative phosphorylation complexes II, III, IV and V, analysed by blue native electrophoresis, were indistinguishable from that of wild-type mitochondria (Supplementary Figs $1 \mathrm{~b}$ and $2 \mathrm{~b}$ ), demonstrating that the mitochondrial genome was functional. (iii) To study if the $m d m 10$ site-specific mutants affected the interactions of the three SAM core components Sam35, Sam 37 and Sam50, we expressed Sam50 with a protein A tag. Sam 35 and Sam 37 were efficiently copurified with Sam50 in all mutant mitochondria like in wild-type mitochondria (Fig. 2a), demonstrating that the $\mathrm{SAM}_{\text {core }}$ complex remained intact. The co-purification of Mdm10 with Sam50 was selectively disturbed in the $\mathrm{Mdm} 10^{\mathrm{Y} 73,75 \mathrm{~A}}$ mutant, but remained unaffected in the other Mdm10 mutant strains (Fig. 2a). To directly analyse the SAM-Mdm10 complex, we performed affinity purification via tagged Sam50 or tagged Mdm10, and analysed the elution samples by blue native electrophoresis. The SAMMdm10 complex was stable in Mdm10Y296A,F298A and $\mathrm{Mdm} 10^{\mathrm{G} 144 \mathrm{~L}}$ mitochondria, and selectively compromised in $\mathrm{Mdm} 10^{\mathrm{Y} 73, \mathrm{Y} 75 \mathrm{~A}}$ mitochondria (Fig. 2b), indicating that Y73/Y75 were required for the association of Mdm10 with the $\mathrm{SAM}_{\text {core }}$ complex. (iv) The TOM-SAM supercomplex, which is transiently formed between TOM and SAM $\mathrm{S}_{\text {core }}$ for the initial transfer of $\beta$ barrel precursors ${ }^{41}$, was analysed by the co-purification of TOM subunits with Sam50. The $m d m 10$ mutants did not disturb formation of the supercomplex (Fig. 2a) in agreement with the observation that Mdm10 is not part of the TOM-SAM supercomplex $^{41}$. (v) Since site-specific mutants of the strip of aromatic residues of Mdm10 disturbed its interaction with ERMES (Fig. 1c), we asked if the mutants destabilized the ERMES complex by probing the interactions of its subunits. We expressed protein A-tagged Mmm1 (ref. 19) in double and triple mutants of the aromatic strip, Mdm10 $1296 \mathrm{~A}, \mathrm{~F} 298 \mathrm{~A}$ and Mdm10 Y296,301A,F298A. Co-purification of $\mathrm{Mdm} 10$ with tagged $\mathrm{Mmml}$ was diminished in the Mdm10 $1296 \mathrm{~A}, \mathrm{~F} 298 \mathrm{~A}$ double mutant and strongly impaired in the Mdm10 ${ }^{\mathrm{Y} 296,301 \mathrm{~A}, \mathrm{~F} 298 \mathrm{~A}}$ triple mutant, whereas the association of the other core components Mdm12 and Mdm34 with Mmm1 was not or only moderately affected (Fig. 2c and Supplementary Fig. 2c). Mutants of the aromatic strip of Mdm10 thus selectively disturb the interaction of Mdm10 with ERMES without disrupting the interaction of the other ERMES core components.

We conclude that Mdm10 contains separate binding sites for SAM and ERMES, located on opposite surfaces of the $\beta$-barrel (Fig. 2d). The site-specific $m d m 10$ mutants selectively affect the interaction with either SAM or ERMES, and thus represent a system to experimentally dissect SAM- and ERMES-specific functions. 
a

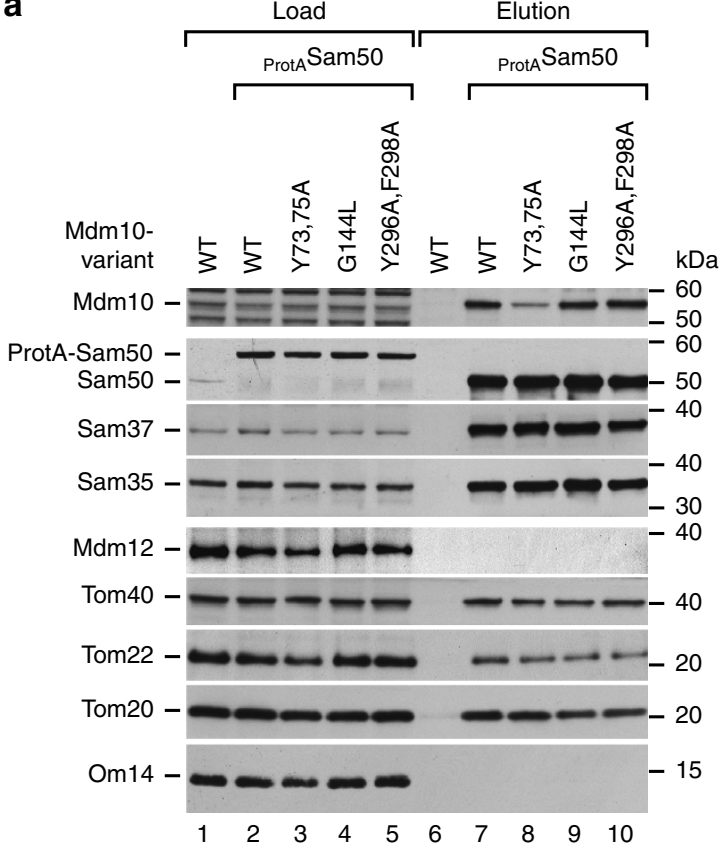

C

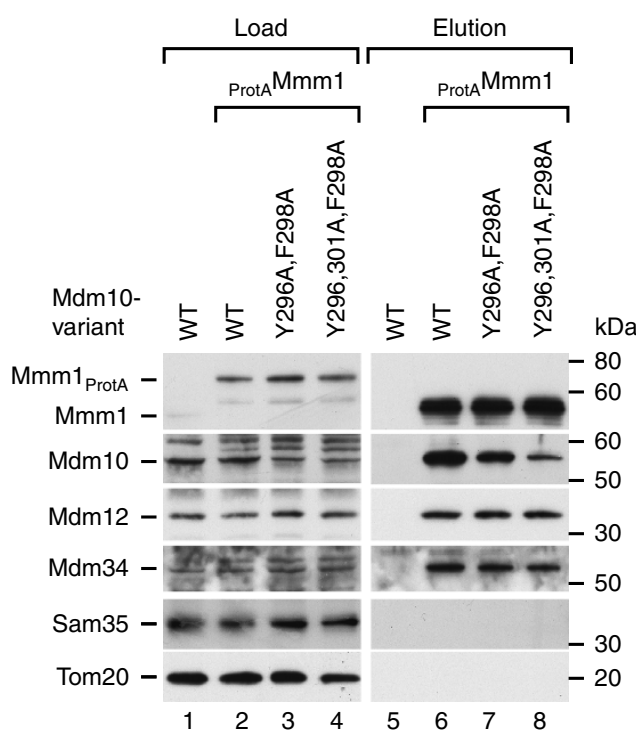

b
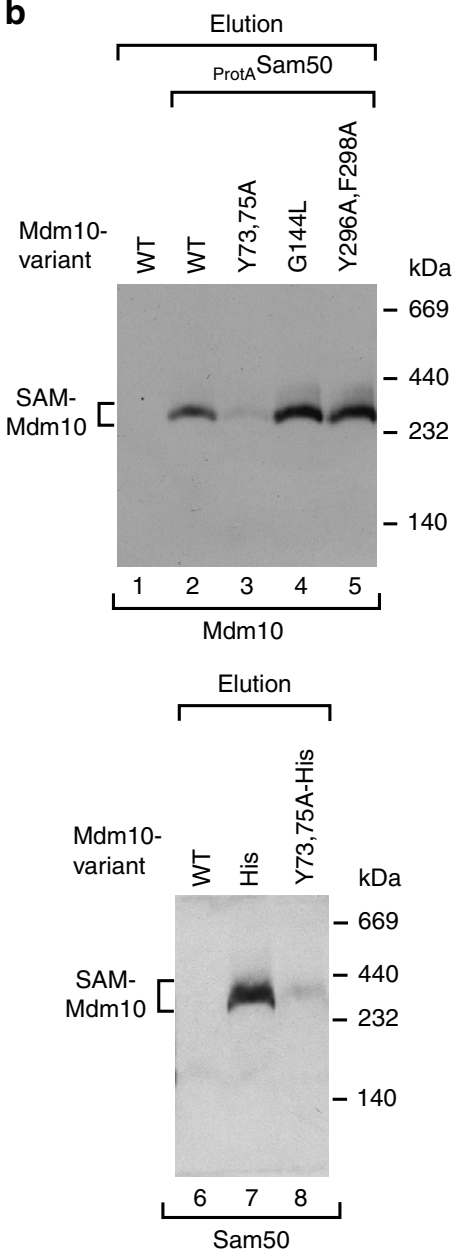

d

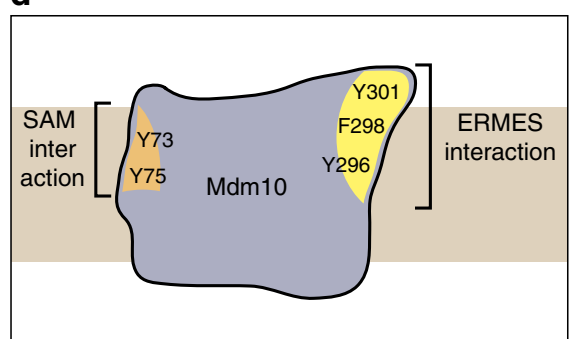

Figure 2 | SAM and ERMES bind to different sides of the Mdm10 $\beta$-barrel. (a) Whole-cell extracts of wild-type (WT) and ProtASam50 cells expressing the indicated $m d m 10$ mutant forms were solubilized with digitonin and subjected to affinity purification using IgG antibodies. Samples were analysed by SDS-polyacrylamide gel electrophoresis (SDS-PAGE) and immunodetection. Load 2\%, elution 100\%. (b) Upper panel: whole-cell extracts of WT and ProtASam50 cells expressing the indicated mdm10 mutant forms were solubilized with digitonin and subjected to affinity purification. Elution samples were analysed by blue native electrophoresis and immunodetection with anti-Mdm10 antibodies. Lower panel: mitochondria isolated from WT, Mdm10 His and

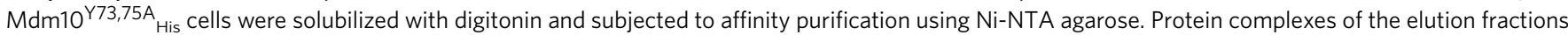
were separated by blue native electrophoresis and analysed by immunodetection with anti-Sam50 antibodies. (c) Whole-cell extracts of WT and ProtAMmm1 cells expressing the indicated mdm10 mutant forms were obtained by cryo-grinding, solubilized with digitonin and subjected to affinity purification using IgG antibodies. Samples were analysed by SDS-PAGE and immunodetection with the indicated antisera. Load $2 \%$, elution $100 \%$.

(d) The hypothetical model indicates that Mdm10 interacts with SAM and ERMES via different regions on the outside of its $\beta$-barrel domain (orange and yellow patches on $\mathrm{Mdm} 10$ ).

ERMES-bound Mdm10 is linked to mitochondrial morphology. Deletion of MDM10 leads to severe alterations of the normal tubular mitochondrial morphology of yeast cells $s^{12,18,23,35,36}$. We asked which population of Mdm10 was crucial for maintaining the tubular mitochondrial network. Mitochondria were stained with the fluorescence dye 3,3'-dihexyloxacarbocyanine iodide $\left(\mathrm{DiOC}_{6}\right)$. The mitochondrial network was normally formed in
Mdm10 $10^{\mathrm{Y} 73,75 \mathrm{~A}}$ yeast, which are impaired in the Mdm10-SAM interaction, as well as in $\mathrm{Mdm} 10^{\mathrm{G} 144 \mathrm{~L}}$ yeast, which are impaired in the Mdm10-Tom7 interaction (Fig. 3a). However, in Mdm10 ${ }^{\mathrm{Y} 296,301 \mathrm{~A}, \mathrm{~F} 298 \mathrm{~A}}$ yeast, which are defective in the Mdm10-ERMES interaction, the tubular mitochondrial network was largely destroyed and a clustering of mitochondria was observed (Fig. 3a). Quantification confirmed the strong alteration 
a
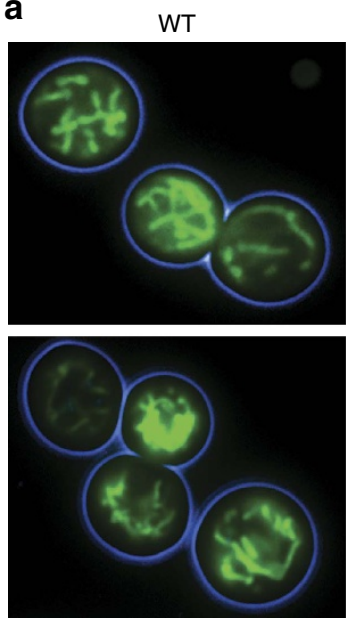

$\mathrm{Mdm} 10^{\mathrm{G} 144 \mathrm{~L}}$
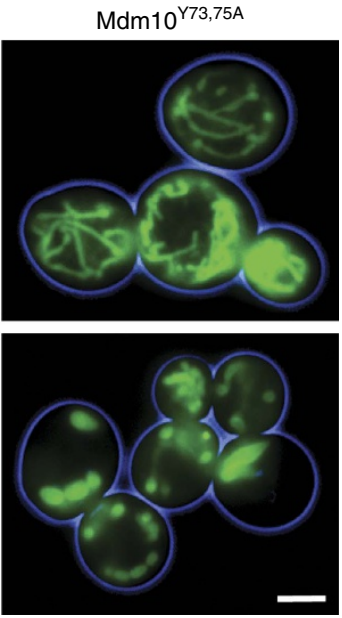

Mdm10 Y296,301A,F298A b

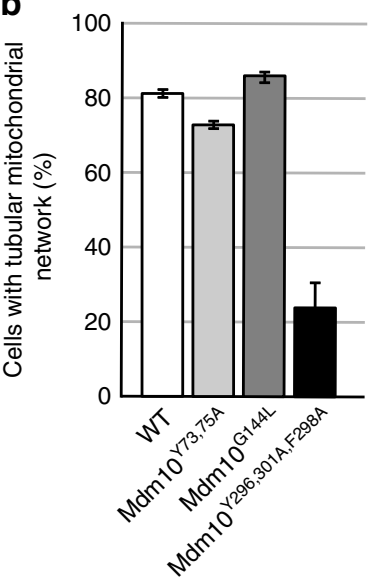

c

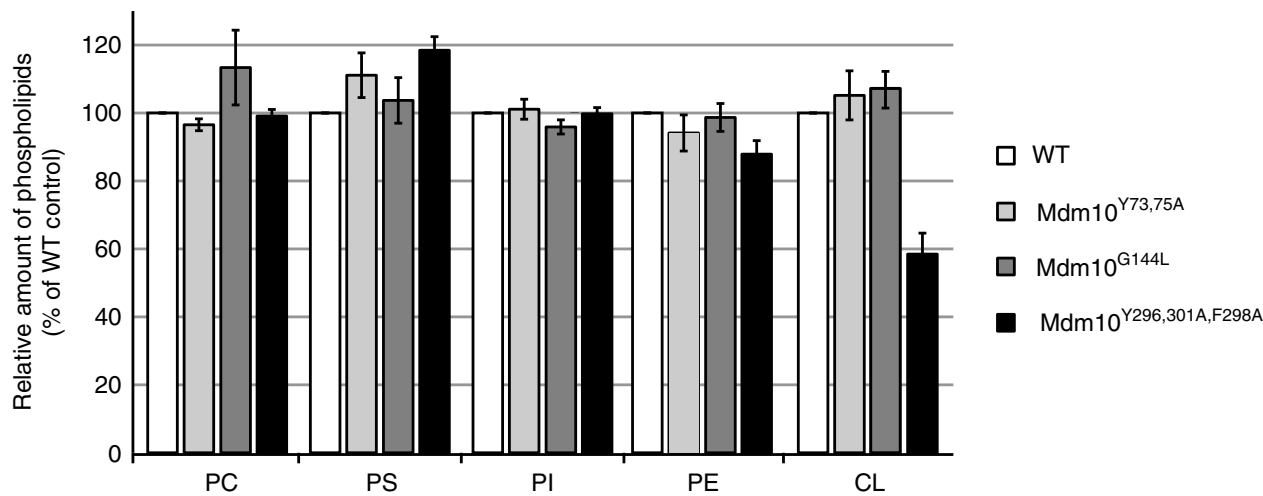

Figure 3 | Mdm10 at the ERMES complex is crucial for maintaining mitochondrial morphology and cardiolipin levels. (a) The mitochondrial morphology of yeast strains expressing wild-type (WT) or mutant forms of MDM10 was visualized by DiOC 6 staining and fluorescence microscopy. Scale bar, $5 \mu$ m. (b) Quantification of mitochondrial morphology based on fluorescence microscopy and staining with DiOC 6 . Relative amounts of cells with tubular network are depicted from three independent experiments with at least 300 cells analysed per strain, shown as mean \pm s.e.m. (c) Yeast cells expressing WT or mutant forms of MDM10 were labelled with [ ${ }^{33} \mathrm{P}$ ]orthophosphate for $90 \mathrm{~min}$ at $37^{\circ} \mathrm{C}$. After isolation of mitochondria, phospholipids were extracted and separated by thin-layer chromatography. Radiolabelled phospholipids were visualized by autoradiography. The amount of each major phospholipid is shown in relation to its WT level (set to $100 \%$ ). Data are presented as mean \pm s.e.m. $(n=3)$.

of the mitochondrial morphology in Mdm10 ${ }^{\mathrm{Y} 296,301 \mathrm{~A}, \mathrm{~F} 298 \mathrm{~A}}$ yeast cells (Fig. 3b).

Mutants of ERMES components lead to an altered phospholipid composition of mitochondria, in particular to decreased levels of the dimeric phospholipid cardiolipin ${ }^{5,23,34,35}$. The biosynthesis of cardiolipin occurs in the mitochondrial inner membrane, yet the precursor lipid phosphatidic acid and further phospholipids have to be transferred from the ER to mitochondria ${ }^{11,42,43}$. Currently, controversial views are discussed if ERMES plays a direct or indirect role in mitochondrial phospholipid homeostasis $5,6,8,17,44$. We used the $m d m 10$ site-specific mutants to determine whether the involvement of Mdm10 in phospholipid homeostasis was linked to ERMES or not. We labelled the yeast cells with $\left[{ }^{33} \mathrm{P}\right]$ orthophosphate and analysed the phospholipid composition of mitochondria. The levels of cardiolipin were significantly diminished in Mdm10 Y296,301A,F298A mitochondria, but not in the other mutant mitochondria (Fig. 3c).

Taken together, the binding of Mdm10 to ERMES is required for maintaining the tubular morphology and phospholipid homeostasis of mitochondria. Mdm10 mutants defective in binding to SAM or Tom7 show wild-type like mitochondrial morphology and phospholipid levels, underscoring the specific functions of the Mdm10-ERMES connection.

Mdm10 forms a mitochondrial membrane anchor of ERMES Mmm1, Mdm12 and Mdm34, but not Mdm10, belong to the tubular lipid-binding protein superfamily. They contain synaptotagmin-like mitochondrial lipid-binding protein (SMP) domains that can bind hydrophobic ligands and are thought to be involved in phospholipid transfer ${ }^{45,46}$. It has been assumed that Mdm34 is an integral protein of the mitochondrial outer membrane $\mathrm{e}^{11,14,42,46}$. Since $\mathrm{Mdm} 12$ has been shown to bridge Mdm34 to the ER-integrated Mmml (ref. 46), the available results indicate that the $\mathrm{Mdm} 34-\mathrm{Mdm} 12-\mathrm{Mmm} 1$ assembly connects mitochondria to the ER and is involved in phospholipid transfer $5,8,34,35,45,46$. Thus, the current model does not leave any relevant role for Mdm10, raising the question why an impaired function of Mdm10 leads to ERMES-specific defects like described for the three SMP domain-containing proteins $5,13,19$.

We directly compared the membrane localization of the four ERMES core components and observed an extraction of Mdm12 
and $\mathrm{Mdm} 34$ at $\mathrm{pH}$ 11.5, whereas $\mathrm{Mdm} 10$ and $\mathrm{Mmm} 1$ remained in the membrane sheets (Fig. 4a, lanes 5 and 6). Thus, in contrast to the current assumption, Mdm34 does not behave as an integral membrane protein. Indeed, using five different prediction programmes (see Methods), we did not detect any transmembrane segment in Mdm34. In a previous study ${ }^{14}, \mathrm{Mdm} 34$ was detected in the membrane fraction after carbonate extraction, however, milder extraction conditions ( $\mathrm{pH}$ 11.0) were used compared with our analysis. Indeed, we found that at milder conditions, the ERMES subunits remained largely membraneassociated; only a fraction of Mdm34 was extracted (Fig. 4a, lanes 2 and 3). These results indicate that Mdm12 and Mdm34 behave as peripheral membrane proteins, which are associated with, but not fully integrated into the lipid phase. Mdm10 is the ERMES core component that is integrated into the lipid phase of the mitochondrial outer membrane.

It is unknown how Mdm10 associates with the three SMP domain-containing ERMES subunits. To determine the organization of ERMES, we systematically analysed the interaction of the ERMES core components on lysis of yeast cell extracts with non-ionic detergent. Tagged Mdm10 co-purified the SMP domain-containing ERMES subunits as expected (Fig. 4b, lane 7$)^{19}$. On deletion of $M D M 34$, the co-purification of Mdm12 and $\mathrm{Mmm} 1$ with Mdm10 was blocked, whereas deletion of MDM12 or MMM1 did not inhibit the interaction between Mdm10 and Mdm34 (Fig. 4b, lanes 8-10). These findings indicate a close association of $\mathrm{Mdm} 10$ and $\mathrm{Mdm} 34$. To obtain independent evidence, we used yeast strains with tagged Mmm1. Deletion of MDM34 inhibited the co-purification of Mdm10 with tagged Mmm1, whereas deletion of MDM10 attenuated but did not block the co-purification of Mdm34 with Mmm1 (Fig. 4c). Mixing experiments outlined in Supplementary Fig. 2d excluded the possibility that Mdm34 and Mdm10 may associate with tagged Mmml after cell lysis. A lack of Mdm12 blocked the interaction of Mdm10 and Mdm34 with Mmm1 (Fig. 4c). Taken together, we conclude that the ERMES core components form a chain of interactions consisting of Mdm10-Mdm34-Mdm12-Mmm1. Mdm10 supports the association of Mdm34 with Mdm12-Mmm1 but is not strictly required for this interaction.

Tom7 binds to Mdm10 released from the SAM complex ${ }^{21,32,36}$, yet opposing views exist if Tom7 is part of the ERMES complex. Yamano et al. $^{21}$ reported that a fraction of Tom7 bound to Mdm10 may be partly associated with ERMES, however, subsequent studies did not detect Tom7 in the ERMES complex $^{15,16}$ and thus the current models of the ERMES complex do not include Tom7 as a stable subunit ${ }^{11,42,47}$. We systematically analysed if small Tom proteins are associated with ERMES by using yeast strains containing tagged Tom5, Tom6 or Tom7. On lysis with non-ionic detergent, only Tom7 pulled down ERMES subunits, whereas all three small Tom proteins pulled down the TOM complex (Fig. 4d, left panel), demonstrating that Tom7 is selectively associated with ERMES. Owing to its small size, Tom7 likely escaped detection in previous studies using mass spectrometry or gel electrophoresis. To determine how Tom7 interacts with ERMES, we used the Mdm10 G144L and Mdm10 $296 \mathrm{~A}, \mathrm{~F} 298 \mathrm{~A}$ site-specific mutants (Fig. 1a). In the Mdm10 $144 \mathrm{~L}$ mutant, Tom7 neither pulled down Mdm10 nor other ERMES subunits (Fig. 4d, right panel). In the Mdm10 ${ }^{\mathrm{Y} 296 \mathrm{~A}, \mathrm{~F} 298 \mathrm{~A}}$ mutant, which is disturbed in the Mdm10-ERMES interaction, Tom7 associated with Mdm10, but not with other ERMES components. The site-specific mdm10 mutants did not inhibit the association of Tom7 with the TOM complex (Fig. 4d, right panel), demonstrating that Tom7 was functional in the mutants. We conclude that the association of Tom7 with ERMES occurs via its binding to Mdm10.
Our findings lead to a new model of the organization of the ERMES complex. Mdm10 forms an integral membrane anchor of ERMES at mitochondria, whereas the peripheral membrane proteins Mdm34 and Mdm12 build the bridge to the ER-anchored Mmm1. In addition, Tom7 bound to Mdm10 is part of the ERMES complex.

SAM-Mdm10 promotes outer membrane protein assembly. Mdm10 is required for the efficient assembly of the TOM complex. Different models have been proposed to describe the role of Mdm10, either by promoting the assembly of the $\beta$-barrel protein Tom 40 or by promoting the import of the receptor Tom22, which contains an $\alpha$-helical transmembrane segment ${ }^{18,21,31,32}$. To determine which population of Mdm10 is involved in protein assembly, we studied TOM assembly in the $m d m 10$ site-specific mutants. The steady-state levels of the fully assembled TOM complex were decreased in $\mathrm{Mdm} 10^{\mathrm{Y} 73,75 \mathrm{~A}}$ mitochondria, which are impaired in the Mdm10-SAM interaction, but not in Mdm10 G144L and Mdm10 $\mathrm{Y296A,F298A}$ mitochondria, which are defective in binding to Tom7 or ERMES, respectively (Fig. 5a). The assembly stages and kinetics of TOM complex formation can be directly monitored by studying the import of the ${ }^{35} \mathrm{~S}$-labelled precursor of Tom 40 into isolated mitochondria. The assembly of Tom 40 occurs via two intermediates that can be resolved by blue native electrophoresis. Intermediate I represents binding of the precursor to the SAM complex in two stages, followed by formation of a Tom40 dimer (intermediate II) that assembles with Tom 22 and small Tom proteins to form the mature TOM core complex $28,32,33$. TOM assembly was strongly diminished in $\mathrm{Mdm} 10^{\mathrm{Y} 73,75 \mathrm{~A}}$ mitochondria, in particular formation of intermediate I and of the mature TOM complex was reduced, whereas in $\mathrm{Mdm} 10 \mathrm{G} 144 \mathrm{~L}$, Mdm10 Y296A,F298A and Mdm10Y296,301A,F298A mitochondria TOM assembly was not or only mildly affected (Fig. 5b,c). Thus, Mdm10 mutant mitochondria that are defective in the Mdm10-SAM interaction show a major defect in TOM assembly, but not Mdm10 mutants that are impaired in binding to Tom7 or ERMES.

The import pathway of the Tom40 precursor involves an initial translocation by the TOM complex to the intermembrane space side, followed by export via the SAM complex and assembly $27,28,41$. Since the levels of the TOM complex were reduced in Mdm10 ${ }^{\mathrm{Y} 73,75 \mathrm{~A}}$ mitochondria, we asked if the inhibitory effect was caused by a defect in this initial translocation, that is, before the action of the SAM complex. However, the initial translocation of $\beta$-barrel precursors to a protease-protected location was only mildly reduced in $\mathrm{Mdm} 10^{\mathrm{Y} 73,75 \mathrm{~A}}$ mitochondria (Fig. 5d), indicating that it was the subsequent SAM- and Mdm10-dependent steps that were mainly impaired in the mutant mitochondria. As control, the import of presequence-carrying preproteins via TOM and the presequence translocase of the inner membrane (TIM23) was not or only mildly affected in $\mathrm{Mdm} 10^{\mathrm{Y} 73,75 \mathrm{~A}}$ mitochondria (Supplementary Fig. 3a). We conclude that the disturbed interaction of $\mathrm{Mdm} 10^{\mathrm{Y} 73,75 \mathrm{~A}}$ with the SAM complex leads to an impaired assembly of the TOM complex.

It was reported that mitochondria lacking $\mathrm{Mdm} 10$ are impaired in the import of the Tom 22 precursor into the mitochondrial outer membrane and that the SAM-Mdm10 complex, but not the $\mathrm{SAM}_{\text {core }}$ complex, binds the precursor of Tom 22 (refs 32,48). However, it has remained controversial if Mdm10 plays a role in Tom22 import or not (refs 18,31,32,48). We performed several assays to address a role of Mdm10 in Tom 22 biogenesis. (i) Insertion of the Tom 22 precursor into the outer membrane was analysed by treatment of mitochondria with 
a

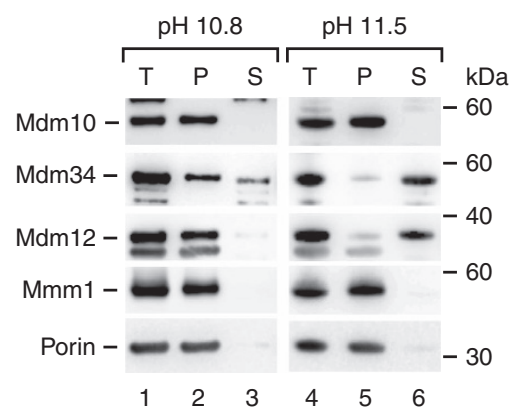

b

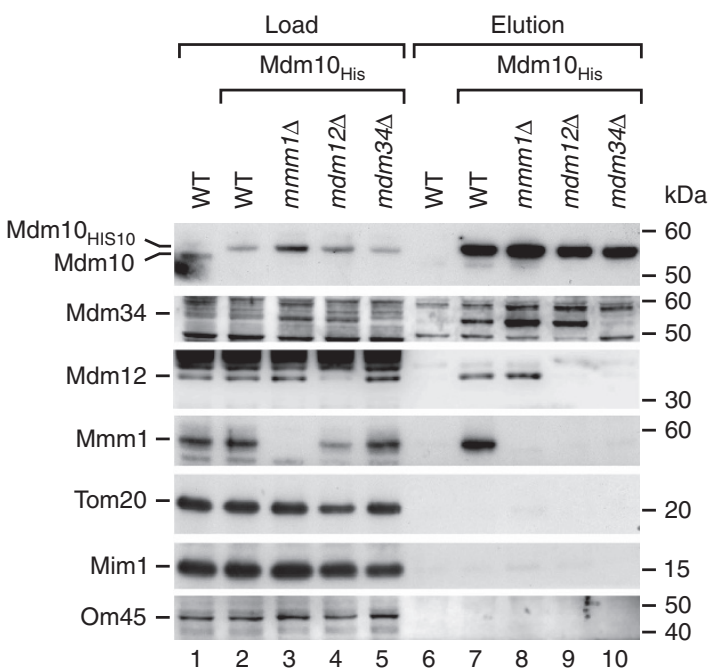

d

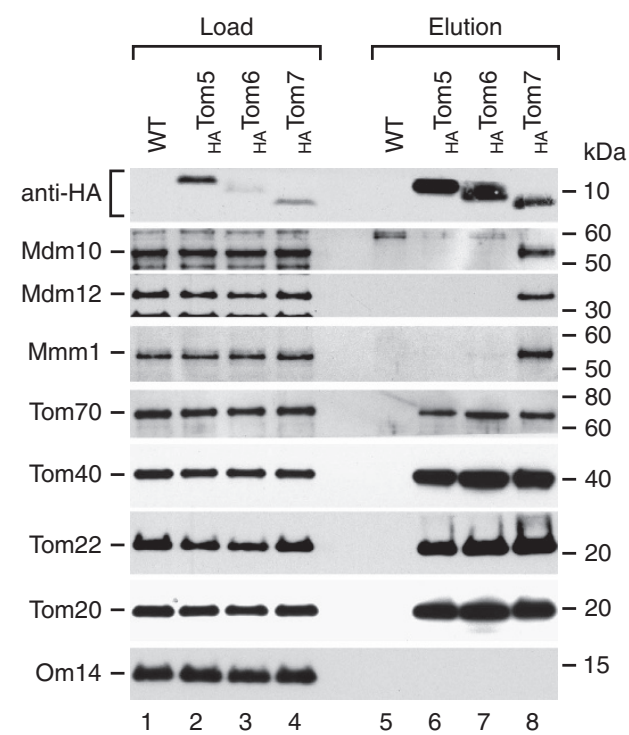

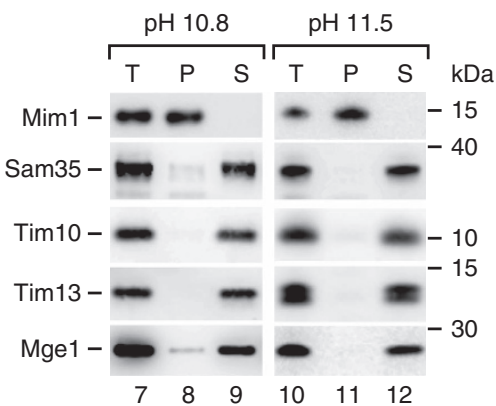

C
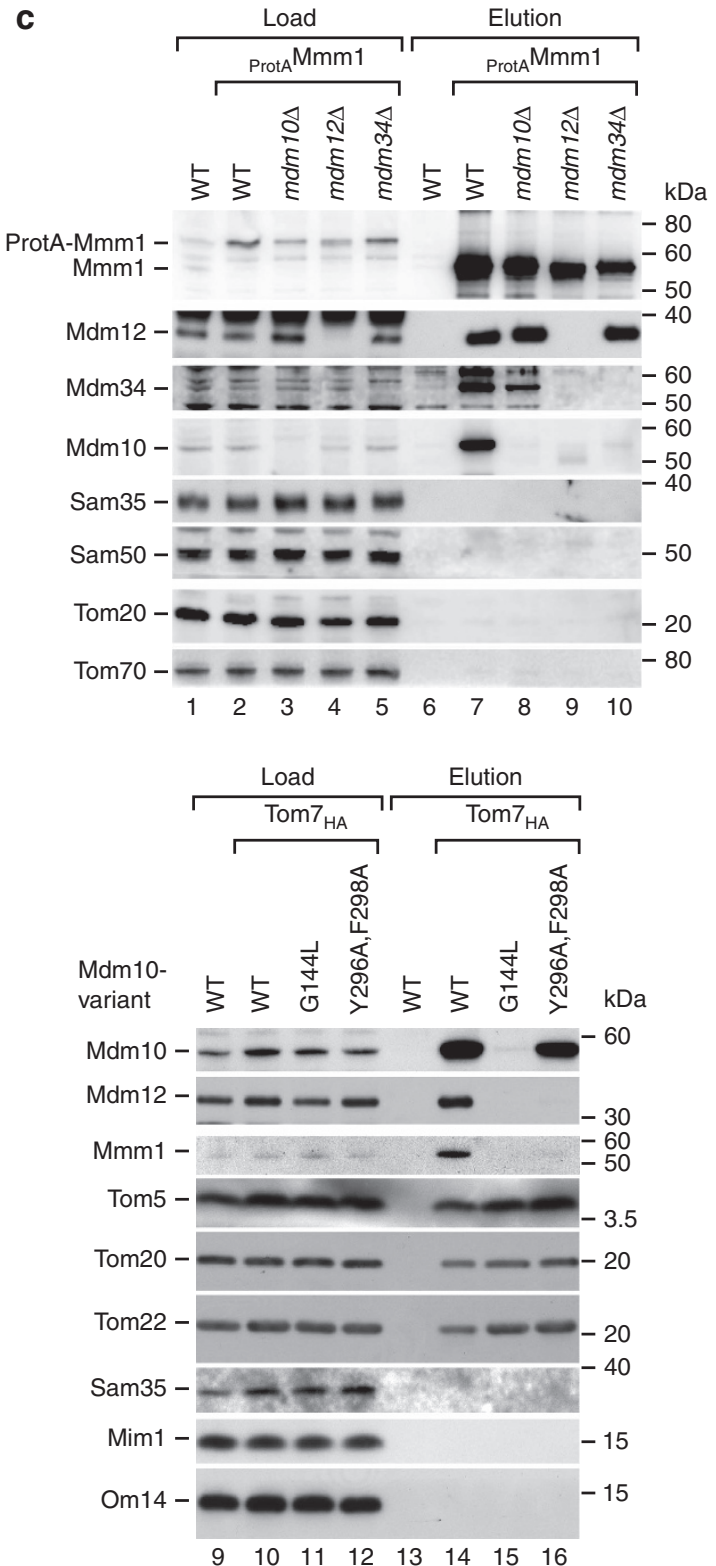

Figure 4 | Mdm10 anchors the ERMES complex in the mitochondrial outer membrane. (a) Mitochondria isolated from wild-type (WT) cells were incubated in $0.1 \mathrm{M} \mathrm{Na}_{2} \mathrm{CO}_{3}$ at $\mathrm{pH} 10.8$ and 11.5. Soluble and membrane-bound proteins were separated by ultracentrifugation. Samples were analysed by SDS-polyacrylamide gel electrophoresis (SDS-PAGE) and immunodetection with the indicated antisera. Comparable amounts of the total sample (T),

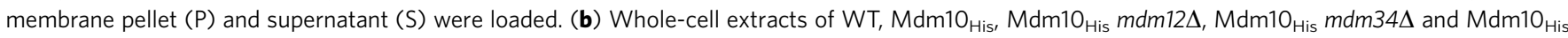
$m m m 1 \Delta$ cells were solubilized with digitonin and subjected to affinity purification using Ni-NTA. Samples were analysed by SDS-PAGE and

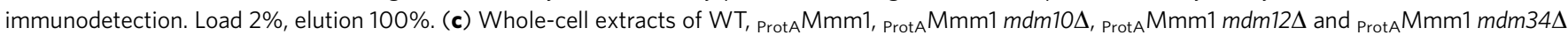
cells were solubilized with digitonin and subjected to affinity purification via IgG-Sepharose. Load 2\%, elution 100\%. (d) Mitochondria isolated from WT,

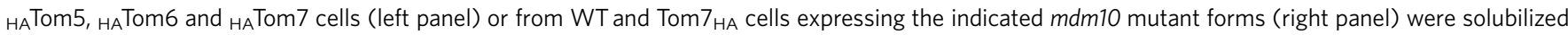
with digitonin and subjected to affinity purification using anti-HA affinity matrix. Load 4\% (left panel), $2 \%$ (right panel); elution $100 \%$. 
a

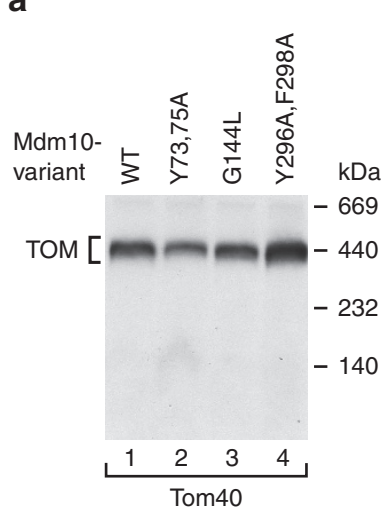

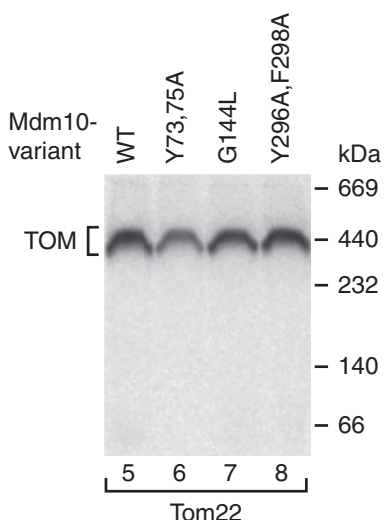

C

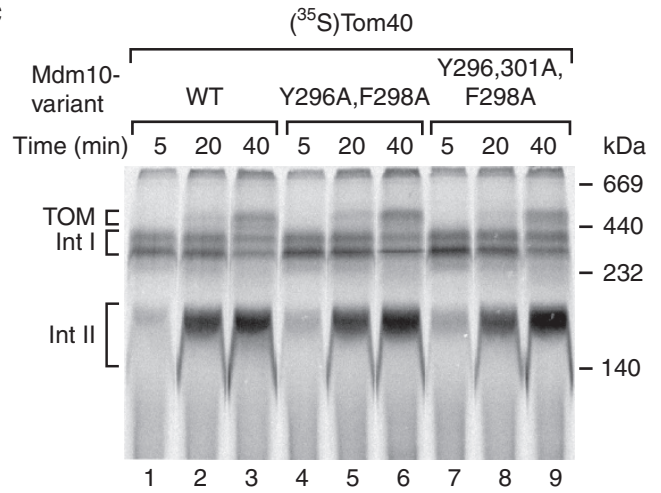

e

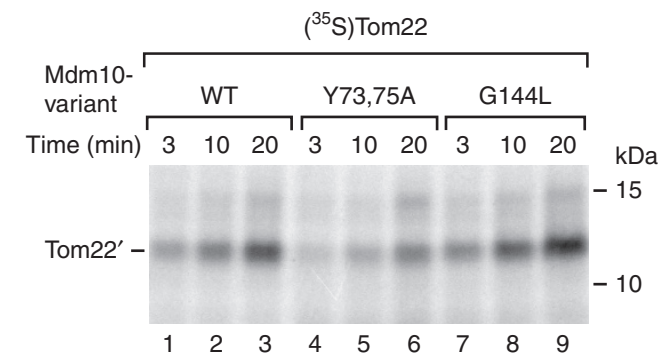

b

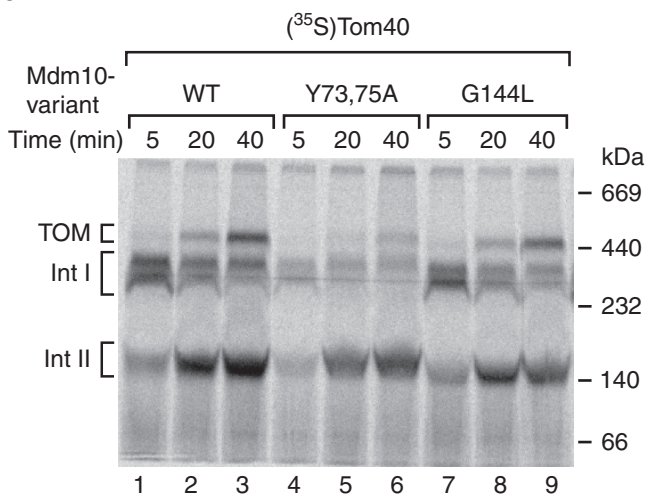

d

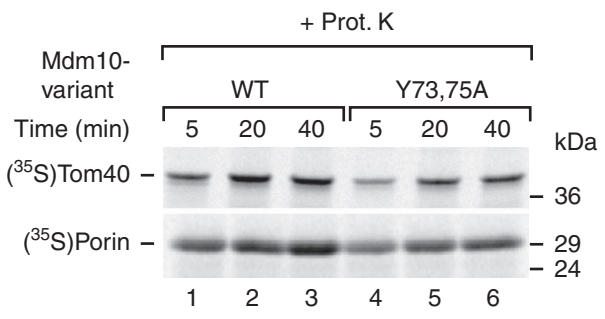

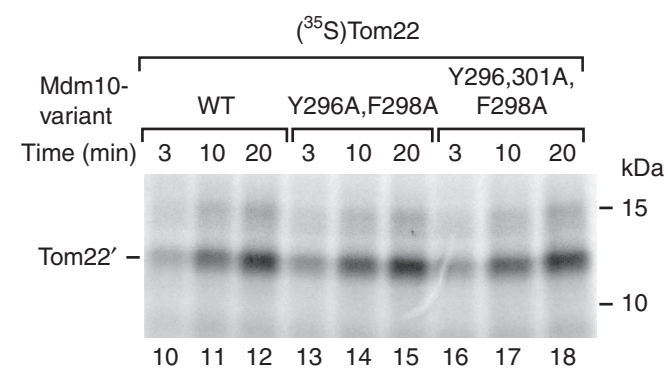

Figure 5 | Mdm10 population bound to SAM mediates biogenesis of the TOM complex. (a) Mitochondria isolated from cells expressing wild-type (WT) or mutant forms of MDM10 were solubilized with digitonin. Protein complexes were separated by blue native electrophoresis. The TOM complex was detected by immunodecoration with antisera against Tom40 and Tom22. (b) $\left.{ }^{35} \mathrm{~S}\right]$ Tom40 was imported into mitochondria, which were isolated from cells expressing WT or mutant forms of MDM10, for the indicated periods. Mitochondria were reisolated, solubilized with digitonin and protein complexes were separated by blue native electrophoresis. Radiolabelled protein complexes were visualized by autoradiography. Int I/II, intermediate I/II. (c) $\left[{ }^{35} \mathrm{~S}\right]$ Tom 40 was imported into isolated mitochondria as described in b. (d) $\left.{ }^{35} \mathrm{~S}\right]$ Tom40 and $\left[{ }^{35} \mathrm{~S}\right]$ Porin were imported into WT and Mdm10 ${ }^{\mathrm{Y} 73,75 \mathrm{~A}}$ mitochondria for the indicated periods. The mitochondria were treated with proteinase $\mathrm{K}$ and analysed by SDS-polyacrylamide gel electrophoresis and autoradiography.

(e) $\left.{ }^{35} \mathrm{~S}\right]$ Tom 22 was imported into WT and the indicated Mdm10 mutant mitochondria, followed by treatment with proteinase K. The protease-protected fragment of membrane-inserted $\left.{ }^{35} \mathrm{~S}\right]$ Tom $22\left(\right.$ Tom $\left.22^{\prime}\right)$ is shown.

protease after the import reaction. The protease removes the $\mathrm{N}$-terminal cytosolic receptor domain of Tom22 and generates a fragment, which consists of the single transmembrane fragment of Tom 22 and its C-terminal intermembrane space domain ${ }^{49}$. Generation of the protease-protected fragment Tom $22^{\prime}$ indicates a proper membrane insertion of the precursor. Membrane insertion of Tom 22 was selectively impaired in Mdm10 $\mathrm{Y73}, 75 \mathrm{~A}$ mutant mitochondria, but not in the other mutant mitochondria (Fig. 5e), indicating that SAM-bound Mdm10 is involved in the efficient import of Tom 22 into the outer membrane. (ii) We asked if the Mdm10 $\beta$-barrel exhibits channel activity. We purified Mdm10 on recombinant expression and reconstituted it into liposomes. The liposomes were fused with a planar lipid bilayer for electrophysiological analysis. We observed a channel activity with a main conductance $\bar{G}_{\text {main }}=480 \mathrm{pS}$ and a slight cation selectivity of $\mathrm{P}_{\mathrm{K}}^{+} / \mathrm{P}_{\mathrm{Cl}}^{-}=2.8: 1 \quad$ (reversal potential $V_{\text {rev }}=21.5 \mathrm{mV}$ ) with a functional unit of three independently gating pores (Fig. 6a,b). The main conductance is in a similar range as that of the Tom 40 and Sam50 channels ${ }^{27,50-52}$. Addition of the full-length precursor of Tom 22 led to a strong stimulation of the gating frequency of the channel (flickering) (Fig. 6c,d). Various control proteins, including the cytosolic domain of Tom22, Tom7 that binds to the outside of the Mdm10 $\beta$-barrel (Figs $1 \mathrm{c}$ and $4 \mathrm{~d})^{21}$ and the multispanning outer membrane protein Om14 (ref. 53), did not affect the channel activity (Fig. 6e). The Tom 22 precursor induced an increase of the maximal conductance of the Mdm10 channel to $\bar{G}_{\text {main }}=550 \mathrm{pS}$ and a change of the functional unit to four independently gating 
a

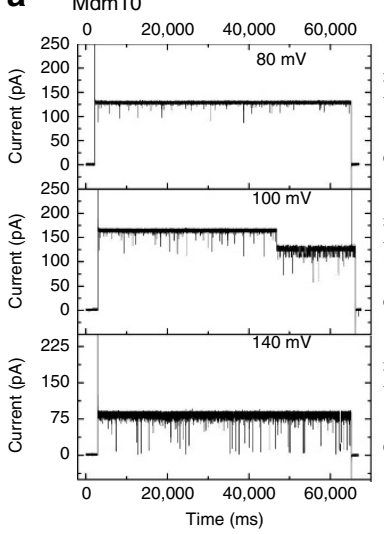

C

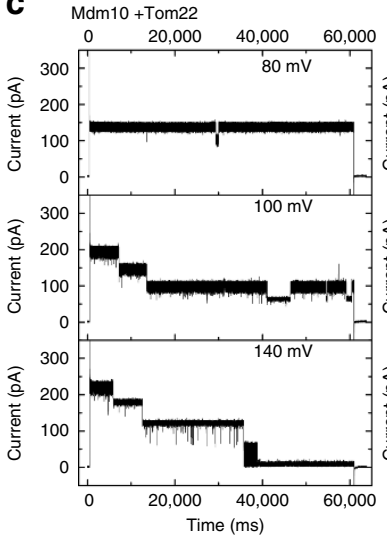

竞

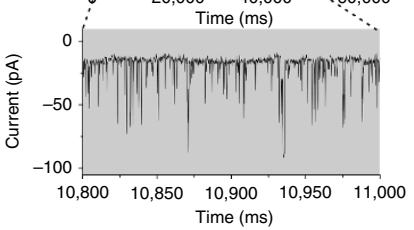

e
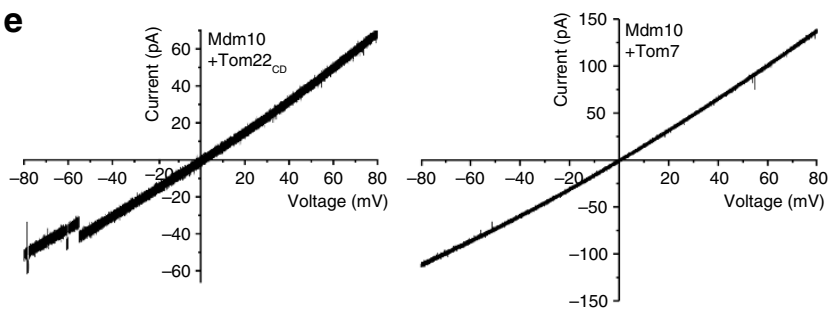

b

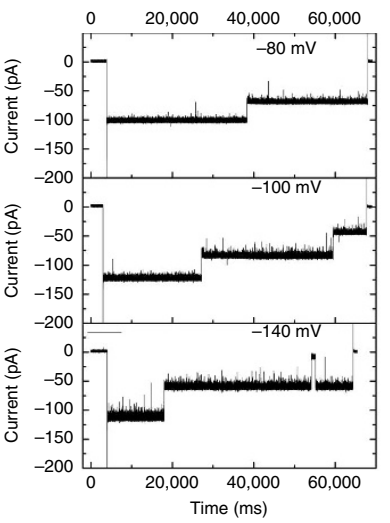

d
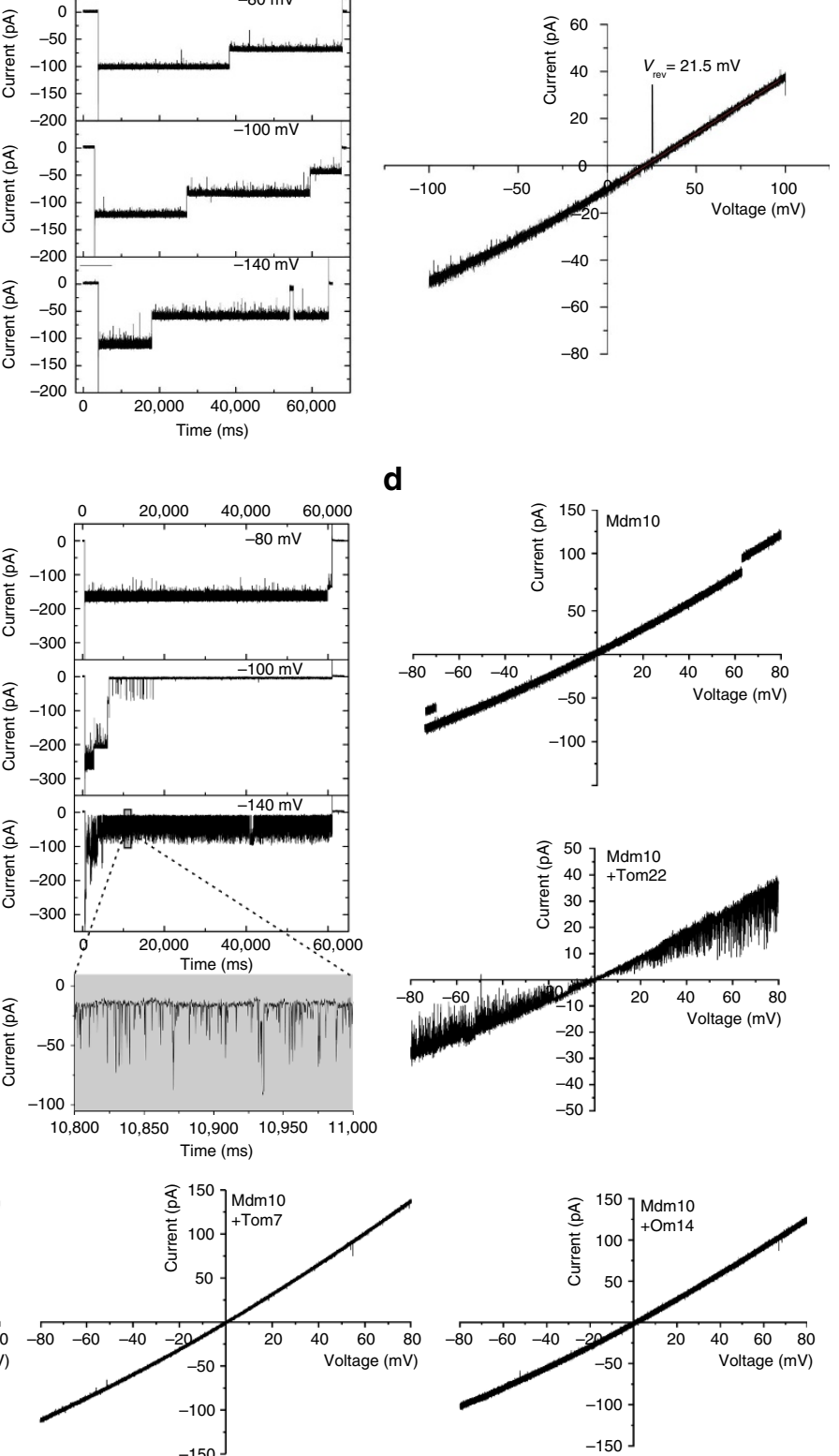

f
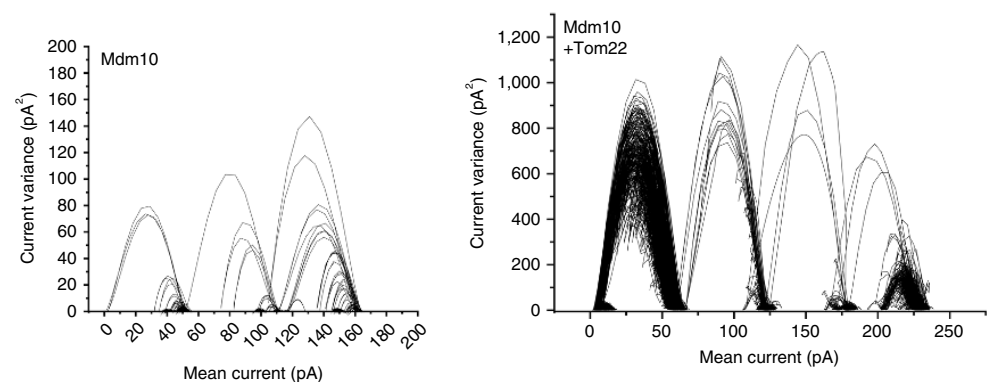

Figure 6 | Mdm10 forms a Tom22-sensitive channel. (a) Single-channel recording under symmetrical buffer conditions (250 mM KCl and $10 \mathrm{mM}$ MOPS-Tris, $\mathrm{pH}$ 7.0) at the indicated $V_{\mathrm{m}}$ from a planar lipid bilayer after a single fusion event of Mdm10 proteoliposomes. (b) Current-voltage relationship of Mdm10 (main conductance) in asymmetric buffer conditions (250/20 mM KCl (cis/trans) and $10 \mathrm{mM} \mathrm{MOPS}$-Tris, pH 7.0). (c) Single-channel recording of Mdm10 under symmetrical buffer conditions as described in a after preincubation of Mdm10 proteoliposomes with full-length Tom22 precursor.

(d) Current-voltage relationship of Mdm10 (main conductance) under symmetrical buffer conditions (upper panel). Mdm10 proteoliposomes were additionally preincubated with Tom22 (lower panel). (e) Current-voltage relationship of Mdm10 (main conductance) under symmetrical buffer conditions after preincubation of Mdm10 proteoliposomes with the cytosolic domain of Tom22 (Tom22 $\mathrm{CD}$ ), Tom7 or Om14. (f) Mean-variance plot from a current recording at $V_{\mathrm{m}}=100 \mathrm{mV}$ of $\mathrm{Mdm} 10$ under symmetrical buffer conditions (left panel). Mdm10 proteoliposomes were additionally preincubated with Tom22 (right panel). 
pores (Fig. 6f). (iii) Tom 22 lacking the cytosolic domain was expressed as a fusion protein with glutathione $S$-transferase (GST) and purified. On incubation with lysed mitochondria, Tom $22_{\Delta \mathrm{N}}$ pulled down Mdm10 (Supplementary Fig. 3b). Taken together, these results support a role of Mdm10 in the biogenesis of Tom22. Mdm10 forms a channel and the precursor of Tom 22 stimulates the channel activity by increasing the gating frequency and channel conductance. Together with the binding of the Tom 22 precursor to the SAM-Mdm10 complex in organello ${ }^{32,48}$ and the analysis of Tom 22 import and Tom40 assembly (Fig. 5), we conclude that SAM-bound Mdm10 promotes the biogenesis of both Tom 22 and Tom 40.

\section{Discussion}

The mitochondrial outer membrane plays crucial functions in metabolite transport, protein biogenesis, lipid homeostasis and membrane dynamics $1,4,11,42,47,54,55$. The latter three functions have been linked to Mdm10. Since Mdm10 is present in both ERMES and SAM complexes $5,18,19,21,26$, we aimed to dissect the functions of the two Mdm10 populations. We designed site-specific mutants that selectively inhibited the coupling of Mdm10 to either one of the complexes. We found that ERMES and SAM bind to opposite surfaces of the Mdm10 $\beta$-barrel and thus could separate protein biogenesis from lipid homeostasis and membrane morphology (Figs 1a and 7). The Mdm10-ERMES interaction is crucial for maintaining mitochondrial morphology and phospholipid homeostasis, whereas the Mdm10-SAM interaction is required for the biogenesis of outer membrane proteins.

The molecular function of Mdm10 has been unknown. We observed that it plays different roles in the ERMES complex and the SAM complex. In the ERMES core complex, Mdm10 forms an integral membrane anchor in the mitochondrial outer membrane. In contrast to previous assumptions ${ }^{14}$, Mdm34 does not contain a transmembrane anchor in the outer membrane, but behaves as a peripheral membrane protein like Mdm12, whereas the $\beta$-barrel of Mdm10 is integrated into the lipid phase of the outer membrane. Suresh et al. ${ }^{56}$ observed that on prolonged glucose starvation the localization of a large fraction of GFP-tagged Mdm34 shifted from ERMES foci to the cytosol in a reversible manner, supporting the view that Mdm34 is only peripherally attached to the mitochondrial outer membrane.
It has been unclear why Mdm10, which does not contain a lipid-binding domain, is required for mitochondrial phospholipid homeostasis like Mdm34, Mdm12 and Mmm1, which all contain lipid-binding SMP domains ${ }^{5,45,46}$. The architecture of the ERMES complex suggests that the membrane anchor function of Mdm10 is crucial for the function of ERMES, however, it is open if in addition Mdm10 and hydrophobic patches inside its $\beta$-barrel channel $^{38}$ may play a direct role in lipid homeostasis. Tan et al. ${ }^{23}$ showed that overexpression of the mitochondrial outer membrane protein Mcpl restored the mitochondrial morphology of cells lacking Mdm10, however, cardiolipin levels, protein import into mitochondria and cell growth at higher temperature were not fully rescued, indicating that crucial functions of Mdm10 were not suppressed by Mcp1; Mcp1 is not associated with ERMES ${ }^{23}$ and its molecular function is unknown. Interestingly, Kornmann et al. ${ }^{5}$ showed that an artificial tethering construct, which connects ER and mitochondria, restores the mitochondrial morphology of cells lacking Mdm12 or Mdm34, but not of cells lacking Mmm1 or Mdm10. Thus, the artificial tether can replace functions of the two peripheral membrane proteins Mdm12 and Mdm34, but not that of the integral membrane proteins $\mathrm{Mmm} 1$ and $\mathrm{Mdm} 10$ in line with our view that Mdm12 and Mdm34 form the bridge between Mmm1 and Mdm10. Mmm1 and Mdm10 likely perform additional functions that cannot be substituted for by an artificial tether. Taken together, we favour the model that the ERMES complex consists of a chain of interactions from membrane integrated Mdm10 in the mitochondrial outer membrane via the peripheral subunits Mdm34 and Mdm12 to Mmm1 in the ER (Fig. 7).

In the SAM complex, Mdm10 is required for promoting the assembly of the TOM complex. Our analysis of Mdm10 concludes the controversial discussion if it promotes the biogenesis of either Tom40 or Tom22 (refs 18,31,32) by demonstrating that $\mathrm{Mdm} 10$ is required for the biogenesis of both precursor proteins. First, the site-specific mdm10 mutant with a defect in binding to SAM impairs assembly of Tom40. The area of the Mdm10 $\beta$-barrel surface that we identified as binding site for SAM is highly conserved on the Tom40 $\beta$-barrel (Supplementary Fig. 4$)^{38}$. Yamano et al. ${ }^{31}$ proposed that Mdm10 promotes the release of the Tom40 precursor from SAM and thus supports its assembly into the TOM complex. Since the complete $\beta$-barrel is folded in association with $\mathrm{SAM}^{41}$, the conserved SAM-binding site of Tom 40 will be formed.

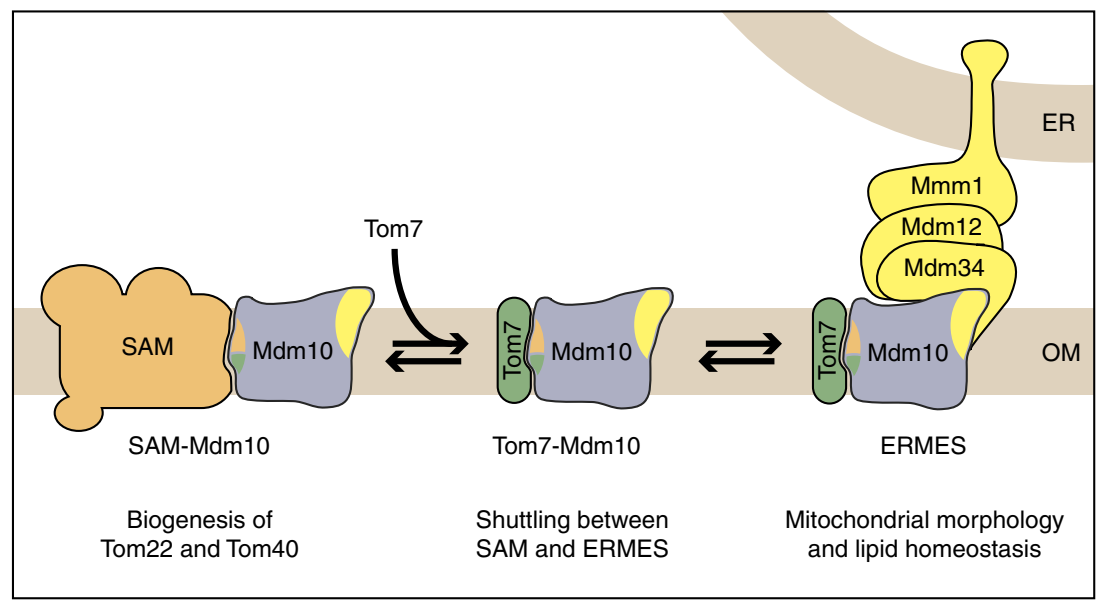

Figure 7 | Hypothetical model of the dynamic interaction of Mdm10 with partner proteins. Mdm10 interacts with SAM and ERMES via opposite surfaces of its $\beta$-barrel domain. Mdm10 forms an integral mitochondrial membrane anchor of ERMES and is required for ERMES functions in maintaining mitochondrial morphology and lipid homeostasis. SAM-bound Mdm10 promotes biogenesis of the TOM complex. The Mdm10-binding sites for Tom7 and SAM are in close proximity. Thus, Tom7 binds only to Mdm10 released from SAM and remains bound to Mdm10 in the ERMES complex. Not shown is the accessory subunit Gem1 that associates with ERMES in substoichiometric amounts. OM, outer mitochondrial membrane. 
Binding of Mdm10 to SAM prevents a re-binding of folded Tom40 to SAM and thus favours an efficient displacement of Tom40 from SAM. Second, the precursor of Tom22 binds to the Mdm10-bound SAM complex in organello, not to the Mdm10-free $\mathrm{SAM}_{\text {core }}$ complex ${ }^{32}$. However, it has been open if Mdm10 plays a direct or indirect role in the biogenesis of Tom22 (refs 18,31). We show that purified Mdm10 forms a $\beta$-barrel channel, which is specifically stimulated by addition of the precursor of Tom22. Insertion of Tom 22 with its $\alpha$-helical transmembrane segment into the outer membrane is impaired in the Mdm10 mutant defective in binding to SAM. Taken together, we conclude that SAM-bound Mdm10 functions in the biogenesis of both Tom22 and Tom40.

Our study also reveals why Tom7 can only bind to SAM-free Mdm10 (refs 21,32). Binding to Tom7 involves a conserved glycine residue of Mdm10 that is located in immediate vicinity to the SAM-binding site (Fig. 1a), suggesting a spatial overlap of the binding regions. Tom7 thus binds to Mdm10, which has been released from the SAM complex, and favours the shuttling of Mdm10 to ERMES ${ }^{21,32}$. Since ERMES binds to the opposite surface of the $\beta$-barrel, Tom7 remains bound to Mdm10 at ERMES and becomes the sixth subunit of ERMES. When the levels of Tom7 are increased, the interaction of Mdm10 with SAM is diminished and its association with ERMES is moderately increased $^{21,32}$. On deletion of TOM7, Mdm10 is redistributed from ERMES to SAM, resulting in moderately reduced levels of Mdm10-ERMES ${ }^{21,32}$. The mitochondrial phospholipid profile is unaltered, but the mitochondrial morphology is disturbed in the absence of Tom7 (refs 21,36). Since the mitochondrial morphology is affected in other tom mutant strains as well ${ }^{18,57}$, this phenotype may be linked to impaired TOM function. Indeed, our site-specific $m d m 10$ mutant specifically affects the binding of Tom7 to Mdm10, whereas Tom7 is still present in the TOM complex to warrant proper protein import and the mitochondrial morphology is not affected. We conclude that unlike Mdm10, Tom7 is not crucial for ERMES function, and a destabilization of Tom7 association with Mdm10 and ERMES in the site-specific mutants does not lead to major defects. Tom7 thus behaves as a non-essential regulatory subunit of ERMES like Gem1 (refs 15-17).

In summary, we can assign four distinct molecular functions to the $\beta$-barrel of Mdm10: (i) binding to Mdm34 and functioning as integral membrane anchor of ERMES; (ii) binding to the SAM complex via a region that is also conserved in Tom40, explaining how Mdm10 favours the release of folded Tom40 from SAM; (iii) formation of a channel that is sensitive to the precursor of Tom22; and (iv) binding to Tom7, which interacts with Mdm10 released from SAM. Importantly, since ERMES and SAM bind to opposite surfaces of Mdm10, we can separate ERMES- and SAM-specific functions of Mdm10 and thus can assign the maintenance of mitochondrial morphology and lipid homeostasis to ERMES, whereas protein assembly is linked to Mdm10 bound to the SAM complex.

\section{Methods}

Yeast strains. The Saccharomyces cerevisiae strains used in this study are listed in Supplementary Table 1 . The point mutations were introduced in the MDM10 open reading frame (ORF) inserted into a pFL39 plasmid by site-directed mutagenesis. Plasmid shuffling was used to generate yeast strains expressing the $m d m 10$ mutant forms or the corresponding wild-type MDM10 (refs 38,41). In the shuffle strain the chromosomal copy of MDM10 was deleted with an ADE2 marker and the pFL39 plasmids encoding $m d m 10$ mutants were transformed in the presence of a YEp352 plasmid encoding wild-type MDM10 and a URA3 selection marker. Yeast cells that have lost YEp352 encoding MDM10 were selected by growth on 5-fluoroorotic acid-containing medium.

To generate yeast strains expressing His-tagged Mdm10, genetic information encoding a deca His-tag was introduced before the stop codon of MDM10 in the pFL39 plasmid. The corresponding yeast strains were generated by plasmid shuffling. To obtain Mdm10 mutant strains expressing ${ }_{\text {ProtA }} \mathrm{Mmml}$ or Tom7 ${ }_{\mathrm{HA}}$, we chromosomally introduced the genetic information coding for the affinity tag in the MDM10 shuffle strain. Subsequently, plasmid shuffling generated yeast strains expressing the Mdm10 mutant forms. Sam50 was tagged with a protein A tag directly in the Mdm10 mutant strains. The genetic information for a triplehaemagglutinin tag was chromosomally integrated in front of the stop codon of TOM7. For yeast strains expressing SAM50 or $M M M 1$ fused to an N-terminal protein A tag, a cassette coding for HIS3MX6-NOP1-ProtA-TEV was chromosomally integrated in front of the SAM50 ORF or MMM1 ORF ${ }^{16,38,41}$. Genetic information encoding a deca-His tag was chromosomally integrated in front of the stop codon of the MDM10 ORF in the $m d m 12 \Delta, m d m 34 \Delta$ or $m m m 1 \Delta$ strains by homologous recombination. Similarly, the nucleotide sequence of HIS3MX6-NOP1-ProtA-TEV was chromosomally integrated in front of the MMM1 ORF in the $m d m 10 \Delta, m d m 12 \Delta$ or $m d m 34 \Delta$ strains by homologous recombination. For the N-terminal tagging of small Tom proteins, the ORFs encoding TOM5, TOM6 or TOM7 were deleted with an URA3 marker. Subsequently, the strains were transformed with a PCR product coding for TOM5, TOM6 or TOM7 and a triple HA-tag after the start codon. HA-TOM5, HA-TOM6 and HA-TOM7 were inserted into their native locus by homologous recombination and replaced the URA3 marker. Transformants were selected by growth on 5-fluoroorotic acid-containing medium.

Growth conditions and isolation of mitochondria. For biochemical analysis, $m d m 10$ mutant strains, strains expressing HA-tagged small Tom proteins and their corresponding wild-type strains were grown on YPG medium (glycerol as carbon source $)^{19}$ at $30^{\circ} \mathrm{C}$ to an early exponential growth phase. For biochemical and fluorescence microscopy experiments involving the Mdm10 $1296,301 \mathrm{~A}, \mathrm{~F} 298 \mathrm{~A}$ mutant, all mutant and wild-type cells were first grown in YPG medium at $30^{\circ} \mathrm{C}$ to mid-log phase and then shifted to $37^{\circ} \mathrm{C}$ for $3 \mathrm{~h}$. Deletion strains of ERMES mutants were grown on YPS (sucrose as carbon source) at $24^{\circ} \mathrm{C}$. Mitochondria were isolated from yeast cells by differential centrifugation. Yeast cells were incubated with $10 \mathrm{mM}$ dithiothreitol in $100 \mathrm{mM}$ Tris/ $\mathrm{H}_{2} \mathrm{SO}_{4}, \mathrm{pH} 9.4$, for $30 \mathrm{~min}$ at $30^{\circ} \mathrm{C}$. After washing with $1.2 \mathrm{M}$ sorbitol, $20 \mathrm{mM} \mathrm{KP}_{\mathrm{i}}, \mathrm{pH} 7.4$, yeast cells were treated with $3 \mathrm{mg}$ zymolyase per g cells for $45 \mathrm{~min}$ at $30^{\circ} \mathrm{C}$ to generate spheroplasts. Spheroplasts were washed with $1.2 \mathrm{M}$ sorbitol, $20 \mathrm{mM} \mathrm{KP}_{\mathrm{i}}, \mathrm{pH} 7.4$, and resuspended in homogenization buffer $(0.6 \mathrm{M}$ sorbitol, $10 \mathrm{mM}$ Tris/HCl, $\mathrm{pH} 7.4,1 \mathrm{mM}$ EDTA, $0.2 \%[\mathrm{w} / \mathrm{v}$ ] bovine serum albumin and $1 \mathrm{mM}$ phenylmethyl sulfonyl fluoride). The cell membrane was ruptured by homogenization of the spheroplasts with 15 strokes using a glass-Teflon homogenizer. Subsequently, cell debris and nuclei were removed by centrifugation $\left(2,000 \mathrm{~g}, 5 \mathrm{~min}, 4^{\circ} \mathrm{C}\right)$. The supernatant was subjected to a second centrifugation step $\left(17,500 \mathrm{~g}, 15 \mathrm{~min}, 4^{\circ} \mathrm{C}\right)$ to pellet mitochondria. The mitochondrial pellet was washed in SEM buffer $(250 \mathrm{mM}$ sucrose, $1 \mathrm{mM}$ EDTA and $10 \mathrm{mM}$ MOPS-KOH, pH 7.2). Finally, mitochondria were resuspended in SEM buffer at a protein concentration of $10 \mathrm{mg} \mathrm{ml}^{-1}$ and shock-frozen in liquid nitrogen. Samples were stored at $-80^{\circ} \mathrm{C}$ until use. The mutant mitochondria analysed contained an intact outer membrane like wild-type mitochondria.

Preparation of total cell extract. For the preparation of total cell extracts, yeast cells were grown to an early logarithmic growth phase and washed twice with water and with lysis buffer $(20 \mathrm{mM}$ Tris- $\mathrm{HCl}, \mathrm{pH} 7.4,0.1 \mathrm{mM}$ EDTA, $50 \mathrm{mM} \mathrm{NaCl}$ and $10 \%$ glycerol). Subsequently, cells were shock-frozen in liquid nitrogen and grinded using a cryomill (Retsch) at $25 \mathrm{~Hz}$ for $10 \mathrm{~min}$. Cell powder was stored at $-80^{\circ} \mathrm{C}$ until use.

Protein import into isolated mitochondria. The precursor proteins for in vitro import were synthesized in a coupled transcription/translation system based on reticulocyte lysate (TNT SP6 quick-coupled transcription/translation kit; Promega). pGEM4z plasmids or RNA encoding proteins of interest were added to the reaction. The proteins were labelled with $\left[{ }^{35} \mathrm{~S}\right]$ methionine. For in vitro import reactions, $\sim 5-10 \%(\mathrm{v} / \mathrm{v})$ of translation lysate were used. The standard import reaction ${ }^{41}$ was performed in import buffer $(3 \%(\mathrm{w} / \mathrm{v})$ bovine serum albumin, $250 \mathrm{mM}$ sucrose, $80 \mathrm{mM} \mathrm{KCl}, 5 \mathrm{mM} \mathrm{MgCl}, 5 \mathrm{mM}$ methionine, $2 \mathrm{mM} \mathrm{KH}_{2} \mathrm{PO}_{4}$ and $10 \mathrm{mM}$ MOPS-KOH, pH 7.2) supplemented with $4 \mathrm{mM}$ ATP and $4 \mathrm{mM}$ NADH. Import reactions were stopped by addition of a mixture of $8 \mu \mathrm{M}$ antimycin $\mathrm{A}, 1 \mu \mathrm{M}$ valinomycin and $20 \mu \mathrm{M}$ oligomycin (final concentrations). In case of outer membrane precursor proteins, transfer on ice stopped the import reaction. To analyse the membrane insertion of $\left[{ }^{35} \mathrm{~S}\right]$ Tom 22 we imported a Tom 22 variant, which contained three additional methionines at the $\mathrm{C}$ terminus. After the import reaction, mitochondria were incubated with proteinase $\mathrm{K}\left(50 \mu \mathrm{g} \mathrm{ml}^{-1}\right.$ final concentration) for $15 \mathrm{~min}$ on ice. The protease was inhibited by addition of phenylmethyl sulfonyl fluoride.

The samples were analysed by SDS-PAGE or blue native electrophoresis, followed by autoradiography. For native analysis, the samples were solubilized with lysis buffer $(20 \mathrm{mM}$ Tris- $\mathrm{HCl}, \mathrm{pH} 7.4,0.1 \mathrm{mM}$ EDTA, $50 \mathrm{mM} \mathrm{NaCl}$ and $10 \%$ glycerol) containing $1 \%(\mathrm{w} / \mathrm{v})$ digitonin for $15 \mathrm{~min}$ on ice. Non-solubilized material was removed by centrifugation and the supernatant was loaded on a blue native gel.

Affinity purification from total cell extracts. For affinity purification out of total cell extracts, yeast strains expressing protein A-tagged Mmm1 or Sam50, and yeast 
strains expressing His-tagged Mdm10 were used. The cell extract was prepared by cryo-grinding. For affinity purification via the protein A tag, the cell powder was solubilized with lysis buffer containing $1 \%(\mathrm{w} / \mathrm{v})$ digitonin ( $1 \mathrm{ml}$ lysis buffer per $100 \mathrm{mg}$ cells) for $45 \mathrm{~min}$ at $4{ }^{\circ} \mathrm{C}$ under constant rotation. After removal of non-solubilized material, the sample was incubated with IgG-Sepharose (GE Healthcare) for $90 \mathrm{~min}$. Unbound material was removed by centrifugation. The beads were washed with an excess of lysis buffer containing $0.1 \%(\mathrm{w} / \mathrm{v})$ digitonin. Bound proteins were eluted by incubation with His-tagged AcTEV Protease (Invitrogen) in lysis buffer containing $0.1 \%(\mathrm{w} / \mathrm{v})$ digitonin for SDS-PAGE analysis or $1 \%(\mathrm{w} / \mathrm{v})$ digitonin for blue native electrophoresis. The elution step was performed overnight at $4^{\circ} \mathrm{C}$ under constant shaking. The His-tagged AcTEV Protease was removed by adding Ni-NTA and further incubation for $30 \mathrm{~min}$ at $4{ }^{\circ} \mathrm{C}$.

For affinity purification of His-tagged Mdm10, the cell powder was solubilized with lysis buffer containing $1 \%(\mathrm{w} / \mathrm{v})$ digitonin and $10 \mathrm{mM}$ imidazole $(1 \mathrm{ml}$ lysis buffer per $100 \mathrm{mg}$ cells) for $45 \mathrm{~min}$ at $4{ }^{\circ} \mathrm{C}$ under constant rotation. After removal of insoluble material, the cell extract was incubated with Ni-NTA for $90 \mathrm{~min}$ and purification was continued as described for lysed mitochondrial extracts.

Affinity purification from lysed mitochondrial extracts. For purification of His-tagged Mdm10-containing complexes, mitochondria were lysed with lysis buffer containing $1 \%(\mathrm{w} / \mathrm{v})$ digitonin and $10 \mathrm{mM}$ imidazole for $15 \mathrm{~min}$ on ice. Insoluble material was removed by centrifugation and the remaining lysate was incubated with Ni-NTA agarose for $60 \mathrm{~min}$ at $4{ }^{\circ} \mathrm{C}$ under constant shaking. Unbound samples were removed and the beads were washed with an excess of lysis buffer containing $0.1 \%(\mathrm{w} / \mathrm{v})$ digitonin and $20 \mathrm{mM}$ imidazole. Bound proteins were eluted with lysis buffer containing $250 \mathrm{mM}$ imidazole and $0.1 \%(\mathrm{w} / \mathrm{v})$ digitonin for SDS-PAGE studies or $1 \%(\mathrm{w} / \mathrm{v})$ digitonin for blue native electrophoresis.

Protein complexes containing HA-tagged small Tom proteins were purified from isolated mitochondria utilizing an HA-affinity tag. Mitochondrial membranes were lysed by incubation with lysis buffer containing $1 \%(\mathrm{w} / \mathrm{v})$ digitonin for $15 \mathrm{~min}$ at $4{ }^{\circ} \mathrm{C}$. Insoluble material was removed by centrifugation. The supernatant was incubated with anti-HA affinity matrix (Roche) for $1 \mathrm{~h}$ at $4{ }^{\circ} \mathrm{C}$ under constant shaking. Unbound material was removed by centrifugation and the beads were washed extensively with lysis buffer containing $0.1 \%(\mathrm{w} / \mathrm{v})$ digitonin. Bound proteins were eluted by incubation with SDS sample buffer.

For co-immunoprecipitation, antibodies against Mdm10 were coupled to protein A-sepharose with $7 \mathrm{mM}$ dimethylpimelidate in $0.1 \mathrm{M}$ sodium tetraborate for $30 \mathrm{~min}$ at room temperature. Mitochondria were lysed by incubation with lysis buffer containing $1 \%(\mathrm{w} / \mathrm{v})$ digitonin for $15 \mathrm{~min}$ at $4{ }^{\circ} \mathrm{C}$. Insoluble material was removed by centrifugation. The supernatant was incubated with anti-Mdm10 coupled Protein A-Sepharose CL-4b (GE Healthcare) beads for $1 \mathrm{~h}$ at $4{ }^{\circ} \mathrm{C}$ under constant shaking. Unbound material was removed by centrifugation, followed by extensive washing of the beads with lysis buffer containing $0.1 \%(\mathrm{w} / \mathrm{v})$ digitonin. Bound proteins were eluted by $0.1 \mathrm{M}$ glycine/ $\mathrm{HCl}, \mathrm{pH} 2.5$. Samples were immediately neutralized with TRIS base and precipitated for SDS-PAGE analysis.

GST fusion constructs consisting of GST, a linker containing a Thrombin cleavage site, and Tom $22_{\Delta \mathrm{N}}$ (amino-acid residues $85-152$ ) or Tom $5_{\Delta \mathrm{N}}$ (amino-acid residues 16-50) were expressed in Escherichia coli and coupled to Glutathione Sepharose $4 \mathrm{~b}$ (GE Healthcare) beads ${ }^{52}$. Mitochondria were lysed by incubation in GST buffer (20 mM HEPES-KOH, pH 7.5, $10 \mathrm{mM} \mathrm{Mg-acetate,} 100 \mathrm{mM} \mathrm{K}$-acetate and $10 \%(\mathrm{v} / \mathrm{v})$ glycerol) containing $1 \%(\mathrm{w} / \mathrm{v})$ digitonin for $15 \mathrm{~min}$ at $4{ }^{\circ} \mathrm{C}$. Insoluble material was removed by centrifugation. The supernatant was incubated with Glutathione Sepharose $4 \mathrm{~b}$ beads coated with GST-Tom $22_{\Delta \mathrm{N}}$, GST-Tom $5_{\Delta \mathrm{N}}$ or GST at $4{ }^{\circ} \mathrm{C}$ under constant shaking. Unbound material was removed, followed by extensive washing with GST buffer containing $0.5 \%(\mathrm{w} / \mathrm{v})$ digitonin. The GST fusion proteins were cleaved overnight at $4{ }^{\circ} \mathrm{C}$ by incubation in GST buffer supplemented with $0.5 \%$ (w/v) digitonin, $2.5 \mathrm{mM} \mathrm{CaCl}_{2}$ and $50-80 \mathrm{U} \mathrm{ml}^{-1}$ thrombin under constant shaking (elution).

Carbonate extraction. Mitochondria were incubated with $0.1 \mathrm{M} \mathrm{Na}_{2} \mathrm{CO}_{3}, \mathrm{pH}$ $10.8-11.5$, for $30 \mathrm{~min}$ at $4{ }^{\circ} \mathrm{C}$. Membranes were separated from the supernatant by ultracentrifugation $\left(136,000 \mathrm{~g}, 30 \mathrm{~min}, 4^{\circ} \mathrm{C}\right)$. Total samples, membrane pellet and supernatant fractions were precipitated with trichloroacetic acid and analysed by SDS-PAGE

Microscopy. The mitochondrial morphology was studied by fluorescence microcopy based on the staining of mitochondria with the fluorescent dye $\mathrm{DiOC}_{6}$ (Invitrogen). Yeast cells were pre-cultivated to mid-exponential phase in YPG medium at $30^{\circ} \mathrm{C}$, and prior imaging were shifted to $37^{\circ} \mathrm{C}$ for $3 \mathrm{~h}$. To stain mitochondria, yeast cells were incubated with DiOC6 following the manufacturer's instructions. $\mathrm{DiOC}_{6}$ is taken up by the mitochondria in a membrane potentialdependent manner. We used the Olympus BX61 microscope equipped with the UPLFLN $\times 100 / 1.3$ objective (Olympus) and F-view charge-coupled device camera (Soft Imaging System) to study the fluorescently labelled cells ${ }^{58}$. The fluorescence of DiOC6 was visualized using a $470 / 40 \mathrm{~nm}$ bandpass excitation filter, a $495 \mathrm{~nm}$ dichromatic mirror and a 525/50 nm bandpass emission filter. $Z$-stack images were collected with $0.5 \mu \mathrm{m}$ intervals along the $Z$ axis and analysed with the Cell-P software (Olympus). For quantification, 300 cells of three independent cultures (at least 50 cells per culture) of each strain were analysed.
Phospholipid analysis. To determine the phospholipid content, yeast cells were grown on YPG and shifted to $37^{\circ} \mathrm{C}$ for $3 \mathrm{~h}$. Subsequently, cells corresponding to $25 \mathrm{OD}_{600}$ were centrifuged and resuspended in a small volume of YPG $\left(5 \mathrm{OD}_{600}\right.$ per ml). Yeast cells were labelled with $190 \mu \mathrm{Ci}\left[{ }^{33} \mathrm{P}\right]$ orthophosphate for $90 \mathrm{~min}$ at $37^{\circ} \mathrm{C}$. Yeast cells were pelleted, washed with water and mitochondria were isolated by differential centrifugation. Phospholipids were extracted with a 2:1 (v/v) mixture of chloroform/methanol. One-dimensional thin-layer chromatography was performed with chloroform/ethanol/water/triethylamine $(30 / 35 / 7 / 35, v / v)$ as mobile phase ${ }^{59}$. Radiolabelled phospholipids were visualized by autoradiography. Phospholipid species were identified by co-migration of phospholipid standards (Avanti). Single phospholipids were quantified with ImageQuant (GE Healthcare).

Electrophysiological measurements. $\mathrm{Mdm} 10_{\mathrm{His}}$ was recombinantly expressed in E. coli BL21 (DE3) RIL cells. E. coli cells were grown at $37^{\circ} \mathrm{C}$ in $\mathrm{LB}$ medium to an $\mathrm{OD}_{600}$ of 0.6 . Subsequently, isopropyl- $\beta$-D-thiogalactoside $(1 \mathrm{mM}$ final concentration) was added to induce expression of $\mathrm{Mdm} 10$ for $4 \mathrm{~h}$ at $37^{\circ} \mathrm{C}$. Cells were collected, lysed under denaturing conditions and soluble cell debris was removed by centrifugation. $\mathrm{Mdm} 10_{\mathrm{His}}$ was purified via $\mathrm{Ni}-\mathrm{NTA}$ agarose and eluted in elution buffer $\left(6 \mathrm{M}\right.$ urea, $100 \mathrm{mM} \mathrm{NaH} \mathrm{PO}_{4}$ and $10 \mathrm{mM}$ Tris/ $\mathrm{HCl}$, $\mathrm{pH}$ 5.9). For reconstitution, liposomes containing a lipid mixture $(50 \% \mathrm{~L}-\alpha$-phosphatidylcholin, $33 \%$ L- $\alpha$-phosphatidylethanolamin, $10 \%$ L- $\alpha$-phosphatidylinositol, $2 \%$ $\mathrm{L}-\alpha$-phosphatidylserin and $5 \%$ cardiolipin) were incubated with urea-denatured Mdm10 in the presence of $1 \%(\mathrm{w} / \mathrm{v})$ SDS. Detergent and urea were removed by dialysis and incubation with Calbiosorb adsorbent ${ }^{60}$. The channel activity was measured in a planar lipid bilayer and analysed as described ${ }^{60} . \bar{G}_{\text {main }}$ values of the Mdm10 channel were calculated from the linear slope of current voltage curves between $\pm 30 \mathrm{mV}$ from bilayer containing a single active Mdm10 channel unit. We used mean-variance plots to calculate the number of gating pores. Mean-variance plots were generated as described ${ }^{60,61}$ using at least five current recordings from three independent preparations.

Tom $7_{\mathrm{His}}$, Tom $22_{\mathrm{His}}$ and $\mathrm{Om} 14_{\mathrm{His}}$ were synthesized in a wheat germ-based cell-free translation system (5Prime) $)^{32}$. Proteins were purified under denaturing conditions. The cytosolic domain of Tom 22 fused to a His-tag was produced in E. coli and purified as described ${ }^{41}$. The proteins were incubated with Mdm10-containing proteoliposomes for $30 \mathrm{~min}$ on ice, followed by electrophysiological analysis ${ }^{60}$.

Miscellaneous. Five prediction programmes were used to search for putative transmembrane segments of Mdm34: DAS transmembrane prediction server (http://www.sbc.su.se/ miklos/DAS/; 1997); HMMTOP Prediction of transmembrane helices and topology of proteins Version 2.0 (http://www.enzim. hu/hmmtop/; 2001); TMHMM Server v. 2.0 Prediction of transmembrane helices in proteins (http://www.cbs.dtu.dk/services/TMHMM-2.0/; 1998); TMpred Prediction of transmembrane regions and orientation (http://www.ch.embnet.org/ software/TMPRED_form.html; 1993); and SOSUI Classification and secondary structure prediction of membrane proteins (http://harrier.nagahama-i-bio.ac.jp/ sosui/; 1998). The homology models of Saccharomyces cerevisiae Mdm10 and Tom40 were derived from Flinner et al. ${ }^{38}$.

Proteins were transferred from blue native gels and SDS-containing gels to polyvinylidene difluoride membranes (EMD Millipore) by semi-dry western blotting. Proteins were detected with specific antibodies (Supplementary Table 2), which were tested against mitochondria from the corresponding mutant strains. Enhanced chemiluminescence was used to detect the immunospecific signals ${ }^{62}$. We used X-ray films (Medix XBU, Foma) or the image reader LAS3000 (FujiFilm) to detect the immunosignals. The STORM phosphoimager system was used to detect ${ }^{35}$ S-labelled proteins by autoradiography. Non-relevant lanes were digitally removed, indicated by separating lines. Uncropped versions of all important immunoblots and gels are presented in Supplementary Figs 5 and 6.

Data availability. The authors declare that data supporting the findings of this study are available within the article and its Supplementary Information. All the other data can be obtained from the corresponding authors upon reasonable request.

\section{References}

1. Dolezal, P., Likic, V., Tachezy, J. \& Lithgow, T. Evolution of the molecular machines for protein import into mitochondria. Science 313, 314-318 (2006).

2. Rugarli, E. I. \& Langer, T. Mitochondrial quality control: a matter of life and death for neurons. EMBO J. 31, 1336-1349 (2012).

3. Shutt, T. E. \& McBride, H. M. Staying cool in difficult times: mitochondrial dynamics, quality control and the stress response. Biochim. Biophys. Acta 1833, 417-424 (2013).

4. Friedman, J. R. \& Nunnari, J. Mitochondrial form and function. Nature 505, 335-343 (2014).

5. Kornmann, B. et al. An ER-mitochondria tethering complex revealed by a synthetic biology screen. Science 325, 477-481 (2009).

6. Elbaz-Alon, Y. et al. A dynamic interface between vacuoles and mitochondria in yeast. Dev. Cell 30, 95-102 (2014) 
7. Hönscher, C. et al. Cellular metabolism regulates contact sites between vacuoles and mitochondria. Dev. Cell 30, 86-94 (2014).

8. Lahiri, S. et al. A conserved endoplasmic reticulum membrane protein complex (EMC) facilitates phospholipid transfer from the ER to mitochondria. PLoS Biol. 12, e1001969 (2014).

9. Naon, D. \& Scorrano, L. At the right distance: ER-mitochondria juxtaposition in cell life and death. Biochim. Biophys. Acta 1843, 2184-2194 (2014).

10. Vance, J. E. MAM (mitochondria-associated membranes) in mammalian cells: lipids and beyond. Biochim. Biophys. Acta 1841, 595-609 (2014).

11. Lang, A., John Peter, A. T. \& Kornmann, B. ER-mitochondria contact sites in yeast: beyond the myths of ERMES. Curr. Opin. Cell Biol. 35, 7-12 (2015).

12. Sogo, L. F. \& Yaffe, M. P. Regulation of mitochondrial morphology and inheritance by Mdm10p, a protein of the mitochondrial outer membrane. J. Cell Biol. 126, 1361-1373 (1994).

13. Berger, K. H., Sogo, L. F. \& Yaffe, M. P. Mdm12p, a component required for mitochondrial inheritance that is conserved between budding and fission yeast. I. Cell Biol. 136, 545-553 (1997)

14. Youngman, M. J., Hobbs, A. E. A., Burgess, S. M., Srinivasan, M. \& Jensen, R. E. Mmm2p, a mitochondrial outer membrane protein required for yeast mitochondrial shape and maintenance of mtDNA nucleoids. J. Cell Biol. 164, 677-688 (2004)

15. Kornmann, B., Osman, C. \& Walter, P. The conserved GTPase Gem1 regulates endoplasmic reticulum-mitochondria connections. Proc. Natl Acad. Sci. USA 108, 14151-14156 (2011).

16. Stroud, D. A. et al. Composition and topology of the endoplasmic reticulummitochondria encounter structure. J. Mol. Biol. 413, 743-750 (2011).

17. Nguyen, T. T. et al. Gem1 and ERMES do not directly affect phosphatidylserine transport from ER to mitochondria or mitochondrial inheritance. Traffic 13, 880-890 (2012)

18. Meisinger, C. et al. The mitochondrial morphology protein Mdm10 functions in assembly of the preprotein translocase of the outer membrane. Dev. Cell 7, 61-71 (2004).

19. Meisinger, C. et al. The morphology proteins $\mathrm{Mdm} 12 / \mathrm{Mmm} 1$ function in the major $\beta$-barrel assembly pathway of mitochondria. EMBO J. 26, 2229-2239 (2007).

20. García-Rodríguez, L. J. et al. Mitochondrial inheritance is required for MEN-regulated cytokinesis in budding yeast. Curr. Biol. 19, 1730-1735 (2009).

21. Yamano, K., Tanaka-Yamano, S. \& Endo, T. Tom7 regulates Mdm10-mediated assembly of the mitochondrial import channel protein Tom40. J. Biol. Chem. 285, 41222-41231 (2010).

22. Murley, A. et al. ER-associated mitochondrial division links the distribution of mitochondria and mitochondrial DNA in yeast. eLife 2, e00422 (2013).

23. Tan, T., Ozbalci, C., Brügger, B., Rapaport, D. \& Dimmer, K. S. Mcp1 and Mcp2, two novel proteins involved in mitochondrial lipid homeostasis. J. Cell Sci. 126, 3563-3574 (2013).

24. Böckler, S. \& Westermann, B. Mitochondrial ER contacts are crucial for mitophagy in yeast. Dev. Cell 28, 450-458 (2014).

25. Boldogh, I. R. et al. A protein complex containing Mdm10p, Mdm12p, and Mmmlp links mitochondrial membranes and DNA to the cytoskeleton-based segregation machinery. Mol. Biol. Cell 14, 4618-4627 (2003).

26. Wideman, J. G. et al. Roles of the Mdm10, Tom7, Mdm12, and Mmm1 proteins in the assembly of mitochondrial outer membrane proteins in Neurospora crassa. Mol. Biol. Cell 21, 1725-1736 (2010).

27. Paschen, S. A. et al. Evolutionary conservation of biogenesis of $\beta$-barrel membrane proteins. Nature 426, 862-866 (2003).

28. Wiedemann, N. et al. Machinery for protein sorting and assembly in the mitochondrial outer membrane. Nature 424, 565-571 (2003).

29. Stojanovski, D., Guiard, B., Kozjak-Pavlovic, V., Pfanner, N. \& Meisinger, C. Alternative function for the mitochondrial SAM complex in biogenesis of $\alpha$-helical TOM proteins. J. Cell Biol. 179, 881-893 (2007).

30. Chan, N. C. \& Lithgow, T. The peripheral membrane subunits of the SAM complex function codependently in mitochondrial outer membrane biogenesis. Mol. Biol. Cell 19, 126-136 (2008)

31. Yamano, K., Tanaka-Yamano, S. \& Endo, T. Mdm10 as a dynamic constituent of the TOB/SAM complex directs coordinated assembly of Tom40. EMBO Rep. 11, 187-193 (2010).

32. Becker, T. et al. Biogenesis of mitochondria: dual role of Tom7 in modulating assembly of the preprotein translocase of the outer membrane. J. Mol. Biol. 405, 113-124 (2011)

33. Shiota, T. et al. Molecular architecture of the active mitochondrial protein gate. Science 349, 1544-1548 (2015).

34. Osman, C. et al. The genetic interactome of prohibitins: coordinated control of cardiolipin and phosphatidylethanolamine by conserved regulators in mitochondria. J. Cell Biol. 184, 583-596 (2009).

35. Tamura, Y. et al. Role for two conserved intermembrane space proteins, Ups1p and Ups2p, in intra-mitochondrial phospholipid trafficking. J. Biol. Chem. 287, 15205-15218 (2012)
36. Meisinger, C. et al. Mitochondrial protein sorting: differentiation of $\beta$-barrel assembly by Tom7-mediated segregation of Mdm10. J. Biol. Chem. 281, 22819-22826 (2006).

37. Bay, D. C., Hafez, M., Young, M. J. \& Court, D. A. Phylogenetic and coevolutionary analysis of the $\beta$-barrel protein family comprised of mitochondrial porin (VDAC) and Tom40. Biochim. Biophys. Acta 1818, 1502-1519 (2012).

38. Flinner, N. et al. Mdm10 is an ancient eukaryotic porin co-occurring with the ERMES complex. Biochim. Biophys. Acta 1833, 3314-3325 (2013).

39. Pusnik, M. et al. The single mitochondrial porin of Trypanosoma brucei is the main metabolite transporter in the outer mitochondrial membrane. Mol. Biol Evol. 26, 671-680 (2009)

40. Guharoy, M. \& Chakrabarti, P. Conserved residue clusters at protein-protein interfaces and their use in binding site identification. BMC Bioinformatics 11, 286 (2010).

41. Qiu, J. et al. Coupling of mitochondrial import and export translocases by receptor-mediated supercomplex formation. Cell 154, 596-608 (2013).

42. Tatsuta, T., Scharwey, M. \& Langer, T. Mitochondrial lipid trafficking. Trends Cell Biol. 24, 44-52 (2014).

43. Lahiri, S., Toulmay, A. \& Prinz, W. A. Membrane contact sites, gateways for lipid homeostasis. Curr. Opin. Cell Biol. 33, 82-87 (2015).

44. Voss, C., Lahiri, S., Young, B. P., Loewen, C. J. \& Prinz, W. A. ER-shaping proteins facilitate lipid exchange between the ER and mitochondria in S. cerevisiae. J. Cell Sci. 125, 4791-4799 (2012).

45. Kopec, K. O., Alva, V. \& Lupas, A. N. Homology of SMP domains to the TULIP superfamily of lipid-binding proteins provides a structural basis for lipid exchange between ER and mitochondria. Bioinformatics 26, 1927-1931 (2010).

46. AhYoung, A. P. et al. Conserved SMP domains of the ERMES complex bind phospholipids and mediate tether assembly. Proc. Natl Acad. Sci. USA 112, 3179-3188 (2015).

47. Klecker, T., Böckler, S. \& Westermann, B. Making connections: interorganelle contacts orchestrate mitochondrial behavior. Trends Cell Biol. 24, 537-545 (2014).

48. Thornton, N. et al. Two modular forms of the mitochondrial sorting and assembly machinery are involved in biogenesis of $\alpha$-helical outer membrane proteins. J. Mol. Biol. 396, 540-549 (2010).

49. Kiebler, M. et al. The mitochondrial receptor complex: a central role of MOM22 in mediating preprotein transfer from receptors to the general import pore. Cell 74, 483-492 (1993).

50. Hill, K. et al. Tom 40 forms the hydrophilic channel of the mitochondrial import pore for preproteins. Nature 395, 516-521 (1998).

51. Suzuki, H. et al. Membrane-embedded C-terminal segment of rat mitochondrial TOM40 constitutes protein-conducting pore with enriched $\beta$-structure. J. Biol. Chem. 279, 50619-50629 (2004).

52. Kutik, S. et al. Dissecting membrane insertion of mitochondrial $\beta$-barrel proteins. Cell 132, 1011-1024 (2008).

53. Burri, L. et al. Integral membrane proteins in the mitochondrial outer membrane of Saccharomyces cerevisiae. FEBS J. 273, 1507-1515 (2006).

54. Neupert, W. \& Herrmann, J. M. Translocation of proteins into mitochondria. Annu. Rev. Biochem. 76, 723-749 (2007).

55. Endo, T. \& Yamano, K. Transport of proteins across or into the mitochondrial outer membrane. Biochim. Biophys. Acta 1803, 706-714 (2010).

56. Suresh, H. G. et al. Prolonged starvation drives reversible sequestration of lipid biosynthetic enzymes and organelle reorganization in Saccharomyces cerevisiae. Mol. Biol. Cell 26, 1601-1615 (2015).

57. Altmann, K. \& Westermann, B. Role of essential genes in mitochondrial morphogenesis in Saccharomyces cerevisiae. Mol. Biol. Cell 16, 5410-5417 (2005).

58. Ieva, R. et al. Mgr2 functions as lateral gatekeeper for preprotein sorting in the mitochondrial inner membrane. Mol. Cell 56, 1-12 (2014).

59. Tamura, Y. et al. Tam41 is a CDP-diacylglycerol synthase required for cardiolipin biosynthesis in mitochondria. Cell Metab. 17, 709-718 (2013).

60. Harsman, A. et al. Bacterial origin of a mitochondrial outer membrane protein translocase: new perspectives from comparative single channel electrophysiology. J. Biol. Chem. 287, 31437-31445 (2012).

61. Patlak, J. B. Measuring kinetics of complex single ion channel data using mean-variance histograms. Biophys. J. 65, 29-42 (1993).

62. Haan, C. \& Behrmann, I. A cost effective non-commercial ECL-solution for Western blot detections yielding strong signals and low background. J. Immunol. Methods 318, 11-19 (2007).

\section{Acknowledgements}

We thank N. Zufall for expert technical assistance. Work included in this study has also been performed in partial fulfilment of the requirements for the doctoral theses of L.E. L.B., V.K., S.P.S. and the bachelor thesis of K.E. This work was supported by the Sonderforschungsbereiche 746 and 1140, the Deutsche Forschungsgemeinschaft (BE 4679/2-1, ME 1921/4-1, PF 202/8-1, WA 681/2-1), the Excellence Initiative of the German federal and state governments (EXC 294 BIOSS; GSC-4 Spemann Graduate 
School), the European Research Council (ERC) Consolidator Grant No. 648235 and an EMBO long-term fellowship (to Ł.O.).

\section{Author contributions}

L.E., Ł.O., L.B., V.K., O.M., S.P.S., K.E., N.F., S.B.S., B.G. and T.B. performed the experiments and analysed data together with C.M., N.W., E.S., R.W. and N.P.; T.B., N.P., E.S., R.W. and L.E. designed and supervised the project; L.E., Ł.O., O.M., S.P.S., V.K., R.W. and T.B. prepared the figures; N.P. and T.B. wrote the manuscript; all authors discussed results from the experiments and commented on the manuscript.

\section{Additional information}

Supplementary Information accompanies this paper at http://www.nature.com/ naturecommunications

Competing financial interests: The authors declare no competing financial interests.
Reprints and permission information is available online at http://npg.nature.com/ reprintsandpermissions/

How to cite this article: Ellenrieder, L. et al. Separating mitochondrial protein assembly and endoplasmic reticulum tethering by selective coupling of Mdm10. Nat. Commun. 7, 13021 doi: 10.1038/ncomms13021 (2016).

(c) (i) This work is licensed under a Creative Commons Attribution 4.0 International License. The images or other third party material in this article are included in the article's Creative Commons license, unless indicated otherwise in the credit line; if the material is not included under the Creative Commons license, users will need to obtain permission from the license holder to reproduce the material To view a copy of this license, visit http://creativecommons.org/licenses/by/4.0/

(C) The Author(s) 2016 